\title{
Effects of familiar music exposure on deliberate retrieval of remote episodic and semantic memories in healthy aging adults
}

\author{
Paul Alexander Bloom ${ }^{1}$, Ella Bartlett ${ }^{2}$, Nicholas Kathios ${ }^{1}$, Sameah Algharazi ${ }^{3}$, \\ Matthew Siegelman ${ }^{1}$, Fan Shen ${ }^{1}$, Lea Beresford ${ }^{1}$, Michaelle Evangeline DiMaggio-Potter ${ }^{1}$, \\ Anshita Singh ${ }^{4}$, Sarah Bennett ${ }^{5}$, Nandhini Natarajan ${ }^{5}$, Hannah Lee ${ }^{1}$, Sumra Sajid ${ }^{1}$, Erin Joyce ${ }^{5}$, \\ Rachel Fischman ${ }^{1}$, Samuel Hutchinson ${ }^{1}$, Sophie Pan², Nim Tottenham ${ }^{1 *}$, \& Mariam Aly ${ }^{1 *}$
}

*These authors share senior authorship

${ }^{1}$ Columbia University

${ }^{2}$ Barnard College of Columbia University

${ }^{3}$ City College of New York

${ }^{4}$ University of Delhi

${ }^{5}$ Teachers College, Columbia University

Please address correspondence to:

Paul Alexander Bloom

Columbia University Psychology

Psychology Department, Columbia University

Schermerhorn Hall 409A, Columbia University, 1180 Amsterdam Ave, New York, NY 10027

Email: paul.bloom@columbia.edu 
1

2

3

4

5

7 in healthy aging. Exposure to familiar music enhances spontaneous recall of memories directly

8 cued by the music, but it is unknown whether such effects extend to deliberate recall more

9 generally - e.g., to memories not directly linked to the music being played. It is also unclear

10 whether familiar music boosts recall of specific episodes versus more generalized

11 semantic memories, or whether effects are driven by domain-general mechanisms (e.g.,

12 improved mood). In a registered report study, we examined effects of familiar music on

13 deliberate recall in healthy adults ages $65-80$ years $(\mathrm{N}=75)$ by presenting familiar music from

14 earlier in life, unfamiliar music, and non-musical audio clips across three sessions. After each

15 clip, we assessed free recall of remote memories for pre-selected events. Contrary to our

16 hypotheses, we found no effects of music exposure on recall of prompted events, though

17 familiar music evoked spontaneous memories most often. These results suggest that effects of

18 familiar music on recall may be limited to memories specifically evoked in response to the music

19 (Preprint and registered report protocol at https://osf.io/kjnwd/). 
Introduction

\section{Music \& enhanced memory recall}

Many people report that certain songs they have heard years before allow them to mentally 'travel back in time' and recall vivid memories from earlier in life (Rossato-Bennett, 2014). This phenomenon suggests that familiar music may have a particularly powerful role in cueing autobiographical memory recall (declarative memory for events in one's life). Indeed, recent work found that approximately $96 \%$ of young adults experienced music-evoked autobiographical memories (MEAMs) while listening to Billboard Top 100 songs released between birth and age 20 , and approximately $30 \%$ of all songs played triggered a MEAM (Janata, 2009; Janata et al., 2007). Though not all familiar songs evoke MEAMs, both younger and older adults experience this phenomenon, and MEAMs can occur for songs that have not been heard in many years (Belfi et al., 2016; Krumhansl \& Zupnick, 2013; Platz et al., 2015; Schulkind et al., 1999).

In concurrence with work on MEAMs, multiple lines of evidence indicate that music facilitates retrieval of content encoded when the music was played (Alonso et al., 2016; Balch et al., 1992; Palisson et al., 2015; Peretz et al., 1998; Wallace, 1991). For example, compared to silence, attaching text to melody during encoding (Ratovohery et al., 2018, 2019; Samson \& Zatorre, 1991; Serafine et al., 1986; Wallace, 1994) or playing background music (Ferreri et al., 2014) enhances word recall. Binding of musical tones to words through singing can also help aphasic patients retrieve and enunciate words and phrases (Kasdan \& Kiran, 2018; Merrett et al., 2019; Schlaug et al., 2008, 2010; Wan \& Schlaug, 2010). Further, music heard during certain 'sensitive periods' - youth and early adulthood in particular-may cue associations to non-musical stimuli experienced around the same time (Krumhansl \& Zupnick, 2013; Schubert, 2016). Taken together, such evidence indicates that music may serve as a context to which perceptual, episodic, or semantic associations can be mapped at encoding, and later retrieved (Schiller et al., 2015; Smith \& Vela, 2001). 
In recent years, both clinicians and researchers have cited such memory-enhancing

52 properties of music in recommending music listening as a potential therapy for patients with

53 Alzheimer's disease or other forms of dementia (Baird et al., 2019; Brotons et al., 1997; Koger

54 et al., 1999; Larkin, 2001; Peck et al., 2016; Sambandham \& Schirm, 1995). Supporting this

55 claim, patients with dementia or severe acquired brain injuries experience MEAMs (Baird \&

56 Samson, 2014; Baird, Brancatisano, et al., 2020; Baird, Gelding, et al., 2020; Baird \& Samson,

57 2009, 2015; Basaglia-Pappas et al., 2013). One group of 29 dementia patients demonstrated

58 better remote autobiographical memory while exposed to background music compared to

59 silence or background cafeteria noise (Foster \& Valentine, 2001). In this study, autobiographical

60 memory was assessed through questions about personal semantic memories (for example,

61 'which school did you attend') developed based on the Mini-Mental State Exam (MMSE;

62 Folstein et al., 1975), and caregivers verified correct answers. In a different experiment, 10

63 patients with mild Alzheimer's disease scored higher on average on the Autobiographical

64 Memory Interview (AMI; Kopelman et al., 1989) following listening to Vivaldi's 'Four Seasons'

65 than following silence (Irish et al., 2006). In addition, effects of music on autobiographical recall

66 were stronger for remote memories (events occurring from 0-20 years of age) than mid-remote

67 (20-50 years) or recent memories ('the recent past or present') across several studies using

68 MMSE-based questions to evaluate retrieval (Foster \& Valentine, 2001; García et al., 2012).

69 The studies mentioned above played all participants the same pieces of music. This

70 leaves open the possibility that the music may have been familiar to some individuals and not

71 others. However, clinical work has emphasized the benefits of individualized music, or music

72 particularly familiar to a given patient (Gerdner, 2000, 2012; Gerdner et al., 2000; Thomas et al.,

73 2017). In two studies, Alzheimer's patients showed better autobiographical memory recall with

74 exposure to self-chosen music relative to experimenter-chosen music (El Haj et al., 2015; El Haj

75 et al., 2012). Those studies used the TEMPau scale to score the specificity of freely recalled

76 autobiographical narratives on a scale from 0-4 (Piolino et al., 2009). Self-chosen music, relative 
77 to experimenter-chosen music, improved autobiographical memory whether it was played

78 before recall (El Haj et al., 2012) or in the background during recall (El Haj et al., 2015). In both

79 of these studies, however, the experimenter-chosen music (la Boheme, performed by Charles

80 Aznavour, and Spring from Vivaldi's Four Seasons) may have been familiar to many

81 participants, so familiarity per se might not explain the benefit for self-chosen music. Although

82 these studies are promising, several other studies failed to find a benefit of putatively familiar

83 music. For example, no benefits to memory were found when examining exposure to

84 researcher-chosen pieces aimed to be familiar (Vivaldi and Handel pieces) compared to "novel"

85 pieces (contemporary compositions by Graham Fitkin). However, in these studies it is unclear to

86 what degree participants were truly familiar with the music in either condition (Foster \&

87 Valentine, 1998; Foster \& Valentine, 2001).

By what mechanism does music affect memory?

While patients with Alzheimer's disease demonstrate enhanced autobiographical

91 retrieval when memories are music-evoked, leveraging such memory enhancements to develop

92 and improve music-based therapies will depend crucially on a deeper understanding of the

93 mechanisms behind such effects (Blackburn \& Bradshaw, 2014; Fang et al., 2017; Hobeika \&

94 Samson, 2020; Peck et al., 2016). For instance, the generality of such music effects is unknown

95 due to a lack of parallel work in healthy participants. Similar memory-enhancing effects of

96 familiar music in healthy individuals might indicate that music plays a more general role in

97 enhancing remote memory retrieval, as opposed to specifically rescuing processes impaired in

98 dementia patients. In addition, research with healthy individuals may allow for examining the

99 mechanisms of music effects with higher statistical power (e.g., number of distinct events

100 recalled per participant, or number of total participants) than is feasible with dementia patients

101 (Halpern \& O'Connor, 2000; Sartori et al., 2004). Thus, parallel work focusing on healthy aging 
102 individuals could enable more rigorous examination of the mechanisms behind music effects 103 observed in patients with dementia.

104 It is certainly possible that different processes might underlie effects of music on memory

105 recall in healthy versus memory-impaired populations. Even if the mechanisms behind memory-

106 enhancing effects of familiar music do not directly translate from healthy individuals to patients

107 with dementia, an understanding of such mechanisms would be useful. In particular, knowledge

108 of whether music can enhance autobiographical retrieval in healthy aging individuals could

109 inform therapies for alleviating declining memory or building cognitive reserve during healthy

110 aging (Fan et al., 2019; Hays et al., 2002; Tucker \& Stern, 2011). More understanding of music

111 effects on memory in healthy individuals may also help inform music-based treatments for other

112 clinical groups, such as patients with amnesia (Baker, 2001, 2009; Baur et al., 2000; Bower \&

113 Shoemark, 2012) or depression (Aalbers et al., 2017; Cross et al., 2012; Hanser \& Thompson,

114 1994; Semkovska et al., 2012). To date, few studies have pursued such questions in an

115 approach tailored for directly studying healthy aging individuals. While most studies of music

116 and autobiographical memory with dementia patients also included control groups, the healthy

117 participants scored at or near ceiling on most of the autobiographical memory measures (e.g.,

118 questions developed from the MMSE, AMI, and TEMPau scale; El Haj et al., 2013, 2015; Irish et

119 al., 2006). Thus, most prior work has lacked tools for measuring autobiographical memory

120 sensitively enough to detect effects of music on recall in healthy individuals.

121 Because little work has addressed whether healthy individuals show improved recall of

122 remote memories following familiar music, the mechanisms underlying this effect are not

123 particularly clear. One possibility is that such boosted recall in patients is primarily the result of

124 domain-general effects. For example, observed effects of music on autobiographical recall in

125 Alzheimer's patients have been attributed to enhanced arousal (Foster \& Valentine, 2001),

126 changes in affect (El Haj, Postal, et al., 2012; García et al., 2012), reductions in anxiety (Irish et

127 al., 2006; Narme et al., 2014) or agitation (Sánchez et al., 2016; Wall \& Duffy, 2010), increased 
128 self-consciousness (Arroyo-Anlló et al., 2013), or improved linguistic function (Brotons \& Koger,

129 2000; El Haj et al., 2013) following music listening. This can be contrasted to a more specific

130 benefit of music, for example if music acts as a mnemonic cue or helps the formation of an

131 attentional state that promotes memory retrieval (Tarder-Stoll, Jayakumar, et al., 2020).

132 Individualized music therapies for such patients have also been suggested for the purpose of

133 reducing stress and agitation alone (Gerdner, 2012), and familiar music tends to evoke more

134 positive emotions in healthy individuals as well (Peretz, 2006; Peretz et al., 1998; Schulkind et

135 al., 1999; Stalinski \& Schellenberg, 2013). Whether observed effects of enhanced recall in

136 patients with memory impairments are the result of a boosted state of retrieval versus more

137 domain-general or affective processes (Balteş et al., 2011) thus remains an open question.

What kinds of memories are enhanced by music?

Understanding of the mechanisms by which music enhances autobiographical recall

141 would also benefit from more detailed characterization of which specific features of recalled

142 memories are enhanced. In particular, there is not yet consensus on whether exposure to music

143 enables recall for specific episodes, more generalized semantic memories, or both (Tulving,

144 1972). García and colleagues (2012) argue that music-related memory enhancement is

145 semantic in nature, based on evidence that music exposure improved recall of personal

146 semantic memories (general facts about one's past and extended events), but not recent

147 episodes (Baird et al., 2018). At the same time, the presence of both semantic and episodic

148 content in MEAMs within healthy individuals suggests that familiar music may be an associative

149 cue for recall of specific events as well (Belfi et al., 2016; Blais-Rochette \& Miranda, 2016; Cady

150 et al., 2008; Ford et al., 2011; Janata et al., 2007). Moreover, Alzheimer's patients scored higher

151 on subscales of the Autobiographical Memory Interview measuring both personal semantic and

152 episodic memory following exposure to music in comparison to silence (Irish et al., 2006).

153 Unfortunately, the evidence from most other patient studies is limited due to the fact that the 
154 autobiographical memory measures used (questions derived from the MMSE or TEMPau scale)

155 do not explicitly distinguish episodic from semantic recall. Ultimately, instruments designed

156 specifically to capture differential episodic and semantic recall will be needed for a better

157 understanding of how music impacts remote memory retrieval.

158 Perhaps most importantly, it is yet unclear whether familiar music cues can enhance

159 recall of autobiographical memories beyond those immediately and involuntarily evoked by the

160 music. In addition to these spontaneously triggered memories (i.e., MEAMs), it is possible that

161 such music may facilitate more deliberate, or 'voluntary', recall of other memories (Jakubowski

162 et al., 2018). If familiar music can boost deliberate recall more generally for autobiographical

163 events beyond those directly and spontaneously evoked by the music, familiar music cues might

164 have far broader clinical potential. As the vast majority of studies on MEAMs in healthy

165 individuals examine only such spontaneously evoked memories (Belfi et al., 2016, 2020;

166 Jakubowski \& Ghosh, 2019; Janata, 2009; Janata et al., 2007; Platz et al., 2015), the limits of

167 music-evoked enhancements to memory retrieval are unknown. It is possible that music may

168 invoke a 'retrieval mode' of increased attention to internal states and intention to retrieve

169 memories (Tarder-Stoll, Jayakumar, et al., 2020). If familiar songs can induce such a particular

170 focus on retrieval, this could enhance both involuntary and voluntary recall of remote

171 autobiographical episodes. This hypothesis is supported by findings that familiar stimuli

172 decrease acetylcholine release in the hippocampus, which promotes a state optimized for

173 memory retrieval (Decker \& Duncan, 2020; Duncan et al., 2019; Duncan \& Shohamy, 2016;

174 Hasselmo \& Schnell, 1994; Meeter et al., 2004).

$175 \quad$ Alzheimer's patients' music-evoked autobiographical memories have been argued to

176 have many features of involuntary memories (e.g., more specific and more quickly retrieved; El

177 Haj et al., 2012). However, that patients also score higher on MMSE and AMI items probing

178 personal semantic memories (e.g., 'where were you born') might indicate broader memory

179 enhancement (Foster \& Valentine, 2001). One group of patients retrieved memories that were 
180 more 'self-defining', or central to their identities, with exposure to self-chosen music compared

181 to experimenter-chosen music (El Haj et al., 2015). Overall, while there is some evidence that

182 familiar music can help patients with dementia deliberately retrieve autobiographical details, it is

183 yet unclear whether familiar music can evoke a state of broadly enhanced voluntary retrieval. If

184 familiar music can invoke such a retrieval mode to boost both involuntary and voluntary recall,

185 such an effect could have broad therapeutic potential for both memory-impaired and healthy

186 aging individuals.

The present study

The present registered report study asked whether familiar music, compared to unfamiliar music or non-musical auditory stimuli, can enhance voluntary retrieval. The

191 participants were healthy older adults 65-80 years old. We played participants clips from

192 individualized playlists of familiar music selected from popular music charts, unfamiliar music,

193 and non-musical audio clips across three study sessions. We sought to test deliberate recall for

194 remote events that were distinct from any memories spontaneously evoked by the clips. We did

195 this by prompting participants after each clip to describe autobiographical events that had

196 already been selected from a list of prompts in a pre-screening call. Because prior work has

197 highlighted larger music effects for remote than recent events (Foster \& Valentine, 2001), all

198 prompts focused on events occurring before age 25. Further, we aimed to examine whether any

199 effects of music on memory retrieval were specific to episodic or semantic recall. To accomplish

200 this, we scored participants' recall of each event for the number of episodic details specific to

201 the event prompted (details 'internal' to the prompted episode) versus more general semantic

202 details (details 'external' to the prompted episode) using Autobiographical Interview procedures

203 (Levine et al., 2002). Finally, we determined whether music also impacted more domain-general 204 processes of mood, and whether differences in mood were associated with episodic or semantic 205 recall. 
In pre-planned analyses (see the Registered Report protocol at https://osf.io/kjnwd/), we

207 estimated effects of both experimenter-manipulated and participant-reported music familiarity on

208 deliberate recall (Table 1 Questions 1-2). Specifically, we examined whether familiar music

209 affected the retrieval of internal episodic details, external semantic details, and their relative

210 proportions. Further, to assess more general effects of music not specific to familiar songs, we

211 estimated how these recall outcomes were impacted in both music conditions in contrast with

212 the no-music condition (Table 1 Question 3). In order to examine the robustness of potential

213 findings, all primary analyses were accompanied by specification curve analyses with pre-

214 registered specification choices (Simonsohn et al., 2015).

215 Most generally, we hypothesized that familiar music would enhance deliberate recall of

216 remote autobiographical memory details in our sample of healthy aging adults. More

217 specifically, we predicted that exposure to familiar music, compared to unfamiliar music, would

218 promote voluntary retrieval of specific events and result in enhanced recall of internal details,

219 relative to external details (see Table 1, hypothesis M1). However, we also tested competing

220 hypotheses that familiar music would specifically enhance retrieval of external details (see Table

221 1, hypothesis A1a), or would increase retrieval of both internal and external details, but not the

222 relative proportion of either detail type (see Table 1, hypothesis $A 1 b$ ). We made similar

223 hypotheses for the effects of both familiar and unfamiliar music in contrast with non-music clips

224 (see Table 1, hypotheses M3, A3a, A3b).

225 


\begin{tabular}{|c|c|c|c|}
\hline Question & Hypotheses & Analyses & Results \\
\hline $\begin{array}{l}\text { 1. Does exposure to } \\
\text { familiar music (in } \\
\text { contrast to unfamiliar } \\
\text { music) impact } \\
\text { subsequent voluntary } \\
\text { retrieval of internal } \\
\text { details, external } \\
\text { details, or the } \\
\text { proportion of internal } \\
\text { details? } \\
\text { *Will be conducted } \\
\text { only if familiarity } \\
\text { manipulation is } \\
\text { successful* }\end{array}$ & $\begin{array}{l}\text { M1: Exposure to familiar music will } \\
\text { increase the number of internal, but not } \\
\text { external, details retrieved, thereby } \\
\text { increasing the proportion of retrieved } \\
\text { details that are internal } \\
\text { A1a: Exposure to familiar music will } \\
\text { increase the number of external, but not } \\
\text { internal, details retrieved, thereby } \\
\text { decreasing the proportion of retrieved } \\
\text { details that are internal } \\
\text { A1b: Exposure to familiar music will } \\
\text { increase the number of both internal } \\
\text { and external details retrieved, but will } \\
\text { not affect the proportion of retrieved } \\
\text { details that are internal }\end{array}$ & $\begin{array}{l}\text { - Bayesian multilevel } \\
\text { linear regression } \\
\text { model with number } \\
\text { of details as } \\
\text { outcome, and } \\
\text { contrasts for } \\
\text { familiar > } \\
\text { unfamiliar music } \\
\text { - Corresponding } \\
\text { specification } \\
\text { curves }\end{array}$ & $\begin{array}{l}\text { - No support for Q1 } \\
\text { hypotheses. } \\
\text { - No effects of familiar } \\
\text { music (versus unfamiliar } \\
\text { music) exposure on } \\
\text { subsequent voluntary } \\
\text { (prompted) recall of } \\
\text { internal details, external } \\
\text { details, or the proportion } \\
\text { of internal details. }\end{array}$ \\
\hline $\begin{array}{l}\text { 2. Is participant-rated } \\
\text { familiarity with } \\
\text { individual songs } \\
\text { associated with } \\
\text { voluntary retrieval of } \\
\text { internal details, } \\
\text { external details, or } \\
\text { the proportion of } \\
\text { internal details after } \\
\text { exposure to those } \\
\text { songs? }\end{array}$ & $\begin{array}{l}\text { M2: Higher ratings of song familiarity } \\
\text { will be related to increases in the } \\
\text { number of internal, but not external, } \\
\text { details retrieved, such that familiarity will } \\
\text { be positively associated with the } \\
\text { proportion of retrieved details that are } \\
\text { internal } \\
\text { A2a: Higher ratings of song familiarity } \\
\text { will be related to increases in the } \\
\text { number of external, but not internal, } \\
\text { details retrieved, such that familiarity will } \\
\text { be negatively associated with the } \\
\text { proportion of retrieved details that are } \\
\text { internal } \\
\text { A2b: Higher ratings of song familiarity } \\
\text { will be related to increases in the } \\
\text { number of both internal and external } \\
\text { details, but not the proportion of } \\
\text { retrieved details that are internal }\end{array}$ & $\begin{array}{l}\text { - Bayesian multilevel } \\
\text { linear regression } \\
\text { model with number } \\
\text { of details as } \\
\text { outcome, contrasts } \\
\text { for a } 1 \text {-unit } \\
\text { increase in } \\
\text { familiarity rating } \\
\text { - Corresponding } \\
\text { specification } \\
\text { curves }\end{array}$ & $\begin{array}{l}\text { - No support for Q2 } \\
\text { hypotheses } \\
\text { - No associations } \\
\text { between familiarity with } \\
\text { individual songs and } \\
\text { voluntary (prompted) } \\
\text { retrieval of internal } \\
\text { details, external details, } \\
\text { or the proportion of } \\
\text { internal details. }\end{array}$ \\
\hline $\begin{array}{l}\text { 3. Does exposure to } \\
\text { music (in contrast to } \\
\text { non-music clips) } \\
\text { impact subsequent } \\
\text { voluntary retrieval of } \\
\text { internal details, } \\
\text { external details, or } \\
\text { the proportion of } \\
\text { internal details? }\end{array}$ & $\begin{array}{l}\text { M3: Exposure to music will increase the } \\
\text { number of internal, but not external, } \\
\text { details retrieved, thereby increasing the } \\
\text { proportion of retrieved details that are } \\
\text { internal } \\
\text { A3a: Exposure to music will increase } \\
\text { the number of external, but not internal, } \\
\text { details retrieved, thereby decreasing the } \\
\text { proportion of retrieved details that are } \\
\text { internal } \\
\text { A3b: Exposure to music will increase } \\
\text { the number of both internal and external } \\
\text { details retrieved, but will not affect the } \\
\text { proportion of retrieved details that are } \\
\text { internal }\end{array}$ & $\begin{array}{l}\text { - Bayesian multilevel } \\
\text { linear regression } \\
\text { model (same } \\
\text { model as Q1) with } \\
\text { number of details } \\
\text { as outcome, and } \\
\text { contrasts for both } \\
\text { music conditions > } \\
\text { no music } \\
\text { - Corresponding } \\
\text { specification } \\
\text { curves }\end{array}$ & $\begin{array}{l}\text { - No support for Q3 } \\
\text { hypotheses. } \\
\text { - No effects of music } \\
\text { (versus non-music clips) } \\
\text { exposure on } \\
\text { subsequent voluntary } \\
\text { (prompted) recall of } \\
\text { internal details, external } \\
\text { details, or the proportion } \\
\text { of internal details. }\end{array}$ \\
\hline
\end{tabular}

226 Table 1: Main questions and corresponding hypotheses, planned analyses, and results. Main

227 hypotheses are labeled with M (e.g., M1) and alternative hypotheses are labeled with A (e.g., A1a). 


\section{Materials and Methods}

Methods were preregistered and accepted in-principle as a Stage 1 Registered Report

230 protocol on February 11, 2021. The full protocol can be found at https://osf.io/kjnwd/.

232 Participants

233 We recruited healthy adults between ages $65-80$ years. Recruitment continued until our

234 target $\mathrm{N}=75$ was reached for participants meeting all inclusion criteria (see Supplemental Fig.

235 1). We screened a total of 112 participants to meet our target sample size and accrual criteria.

236 Participants were recruited through paper and electronic newsletters at retirement communities,

237 social media (Facebook), paper flyers posted in New York City, and word of mouth. Because of

238 the ongoing COVID-19 pandemic, all interactions with participants were conducted remotely via

239 Zoom videoconferencing software. Participant consent was obtained via REDCap before the

240 pre-screening call, and participants had opportunities to ask any questions about the consent

241 form before starting study procedures. Participants were compensated $\$ 20 /$ hour for their time

242 (following the end of their participation in the study) via electronic gift cards.

243 Participants reported their ages in years, and their gender, race, and ethnicity in open-

244 ended questions (all verbal reports; see Supplemental Table 1). Participants also reported their

245 annual household income and level of education through multiple-choice questions (see

246 Supplemental Tables 3-4). Overall, the included participants were highly educated, with 74 out

247 of 75 participants reporting at least some form of postsecondary education. 73 participants were

248 in the United States at the time of participation, and 2 were in Canada.

250 Pre-screening call

251 Study inclusion criteria were: (1) willingness to schedule three videoconference memory

252 interview sessions, (2) fluency in English, (3) age between 65-80 years, (4) no known 
253 neurological conditions or hearing impairments, (5) access to a computer, internet connection,

254 and a quiet space, (6) memory for a sufficient number of early-life events (details below), (7)

255 reporting having listened to a sufficient number of popular music artists before age 25 (details

256 below), and (8) a score of 16/22 or higher on the T-MoCA. In addition to the above criteria, we

257 aimed for nearly equal proportions of participants identifying as male and female. To ensure

258 this, we capped accrual of any gender at 45 participants (60\% of the total sample). We also

259 aimed to recruit a sample as racially heterogeneous as the 2019 US population, such that at

260 least 19/75 participants ( 25\%) identified as a race other than White (census.gov, 2019).

261 Participants first took part in a Zoom call to determine study eligibility and provide

262 information for selecting participant-specific music stimuli and memory probes. Participants

263 were encouraged to find a quiet and private space with strong internet access to conduct this

264 call. Experimenters kept their video feeds on for the duration of all calls with participants (unless

265 there were connection issues that were resolved by turning video off), and participants had the

266 option to keep their cameras on or off. At the start of the pre-screening call, experimenters first

267 offered any necessary support for navigating the Zoom software, thanked participants for joining

268 the call, troubleshot any technological or call quality issues, and read participants a short

269 overview of the study. Participants were then asked about eligibility criteria 1-5.

270 Next, participants were asked to report on the degree of early-life exposure to different

271 musical artists to guide selection of participant-specific clips for the familiar music condition.

272 Experimenters read participants a list of musical artists who had songs ranked on the Billboard

273 Hot 100 United States year-end charts between 1946-1983 (see https://osf.io/r3sxd/ for the full

274 list of songs and artists, and for more music list details see https://osf.io/jvb3m/). The artists on

275 these lists were those who released charting songs when participants were ages 5-9 years

276 (childhood), ages 14-18 years (adolescence), and ages 20-25 years (early adulthood). We

277 selected these age ranges to maximize the likelihood that participants would have been familiar

278 with popular music released during these periods in life (Krumhansl \& Zupnick, 2013; Schulkind 
279 et al., 1999; Spivack et al., 2019). Music heard during these age ranges may also be more

280 integral to the development of participants' sociocultural identities (Miranda et al., 2015; Stras,

281 2011). Participant-specific lists contained the 30 artists with the most songs ranked on the top

282100 chart for each respective time period. If artists were redundant (e.g., in the top 30 across

283 multiple time periods), more artists were added such that each list contained 30 unique artists

284 (additional artists were added for the time period for which redundant artists had fewer songs on

285 the charts). For each artist, participants reported how much they listened to that artist from birth

286 to age 25 (either 0 = 'never heard of this artist', or a numerical scale from 1- 'barely listened' to 5-

287 'very frequently listened'). To increase the likelihood that all study participants were familiar with

288 the music clips in the familiar music condition, only participants who gave ratings $\geq 3$ for at least

289 five artists in each of the three time periods were included for participation in the study.

290 Next, participants were read a list of events that they may have experienced during each

291 of the three time periods (childhood, adolescence, and early adulthood), and reported whether

292 or not they could recall a memory of each specific event (Materials available at

293 https://osf.io/6d3hr/). Events were specific to a certain developmental time period (e.g., 'Your

294 high school graduation', or 'A time receiving a holiday present in childhood'). Events were split

295 into three distinct time periods to ensure that participants retrieved memories from a distribution

296 of times early in life, rather than just one span of a few years. We did not include any events

297 occurring later in life to ensure that all probed memories are of remote events (Acevedo-Molina

298 et al., 2020; St. Jacques \& Levine, 2007). Participants were told to say 'no' to any events that

299 they knew happened in their lives but could not recall specifically, or events they did not feel

300 comfortable discussing later in detail. We encouraged participants to provide quick responses

301 (within 10s) to these prompts and not to dwell on any event in detail. Participants who reported

302 being able to recall at least 15 events (out of 50 possible) in each time period were eligible for

303 participation. This inclusion criterion was meant to ensure that participants would be able to 
304 complete a sufficient number of trials for adequate statistical power (see Power Calculations in 305 Supplement).

Lastly, participants completed the telephone version of the Montreal Cognitive

307 Assessment (T-MoCA) protocol to assess cognitive health (Nasreddine et al., 2005; Pendlebury

308 et al., 2013). The T-MoCA is equivalent to the standard MoCA with all visual items removed,

309 and participants can receive a maximum score of 22. We used a cutoff of 16 points or higher

310 (out of 22 possible) for inclusion, and all prescreened participants scored at or above this cutoff.

311 This cutoff was chosen based on the fact that some pilot participants scored as low as $70 \%$

312 correct on the full MoCA ( $87 \%$ is the usual cut-off for healthy cognition), but no pilot participants

313 struggled to understand the instructions or remember events in response to memory prompts.

314 We chose $16 / 22$ on the T-MoCA as a cutoff to roughly match this $70 \%$ correct threshold on the 315 full MoCA.

316 Pre-screening calls on average took 30 minutes. At the end of the pre-screening call,

317 participants who met the inclusion criteria were scheduled for the three music and memory

318 interview sessions. Participants who completed the pre-screening call but did not meet inclusion

319 criteria were paid for their time, but not invited to participate in further sessions.

321 Music clip selection

322 After pre-screening, 15 participant-specific music clips were selected for the familiar

323 music condition. For each time period (childhood, adolescence, and early adulthood), we first

324 selected the 5 artists on the Billboards charts that each participant rated having listened to most

325 (e.g., highest listening ratings on a scale from 0-5 during the pre-screening call). If there were

326 ties in participant ratings, artists with more total songs on the charts during the time period were

327 selected. For each of these 5 artists, we selected their top-charting song released within the

328 respective time period. Only one song was selected from any one artist in each time period,

329 though songs from the same artist (up to a maximum of three, or one in each time period) could 
330 be selected if the artist had songs on the Billboard charts across multiple time periods. Thus,

331 songs in the familiar music condition were selected on a participant-specific basis to maximize

332 potential familiarity without participants selecting songs themselves. This is important because

333 playing music to the participant prior to the memory recall sessions may serve as a reminder or

334 probe for memory, which would then confound our ability to identify how single-shot exposure to

335 familiar music affects retrieval. In addition, we wanted to distinguish effects of music familiarity

336 from potential effects of participants having chosen specific clips, so our procedures were aimed

337 to maximize familiarity without participants directly choosing songs beforehand.

338 One caveat is that this process cannot guarantee that participants were exposed to the 339 music clips during the intended time periods, as opposed to later in life. However, the use of

340 top-charting songs may maximize the likelihood that participants were exposed to them shortly

341 after their release, particularly through radio or television airplay (Bartlett \& Snelus, 1980;

342 Krumhansl, 2017). To test whether participants listened to the familiar music clips most during

343 the approximate time period they were released, we included a manipulation check to assess

344 the timing of music exposure (see Fig. 2).

345 Clips for the unfamiliar music condition were selected from a list of more obscure songs

346 released after the year 2000 to ensure that participants had no exposure to them before age 45

347 (i.e., a 65-year-old participant recruited in 2021), and minimize participant familiarity overall

348 (Schulkind et al., 1999). Before the study, a set of 300 clips was selected by the experimenters

349 for stylistic similarity to the popular music clips used in the familiar music condition (see

350 https://osf.io/6d3hr/). These clips were also selected to have fewer than 500,000 total streams

351 on Spotify, and to neither have appeared on Billboard Hot 100 charts nor received major

352 film/TV/radio features to minimize the likelihood that participants will be familiar with them. For

353 each participant, 15 clips were selected from this list using an algorithm designed to maximize

354 similarity with the corresponding familiar music clips on 6 auditory features generated by Spotify

355 (valence, tempo, loudness, danceability, energy, acousticness, see 
356 https://developer.spotify.com/documentation/web-api/reference/tracks/get-audio-features/) and

357 experimenter-rated genre. For all participants, algorithm-selected playlists for the unfamiliar

358 music condition did not significantly differ from the familiar music condition on any of the

359 auditory features (pairwise t-tests for all participants for all features $p>.05$ ).

360 Clips for the no-music control condition were 15 audio segments from news, weather,

361 and traffic reports selected to be neutral in valence. These clips were the same for all

362 participants. Control condition clips and materials for song clip selection are available via the

363 Open Science Framework at https://osf.io/6d3hr/.

Music and memory interview sessions

Participants each took part in three 60-90 minute sessions (familiar music, unfamiliar

367 music, and no-music control conditions; order counterbalanced across participants) occurring at 368 least one week after the pre-screening call and with at least one week between sessions (see

369 Figure 1). Participants were sent email reminders both one week and one day prior to each

370 session with time details and videoconference call information. At the beginning of each

371 session, experimenters worked with participants to ensure that the call quality was sufficient for

372 participants to clearly hear the music and elaborate on their memories (including playing a

373 sample audio clip to test audio quality). If technological issues prevented a session from

374 starting, sessions were rescheduled. If technological issues caused a call to prematurely end

375 during the middle of a session, experimenters first tried to restore the call to finish the session. If

376 the call could not be completed, experimenters scheduled an additional partial session to finish

377 the incomplete session. If participants missed scheduled sessions, experimenters made three

378 attempts to re-contact participants via email and phone, with the third contact attempt at least 1

379 week after the second. If participants did not respond or indicated that they did not want to

380 continue in the experiment, they were regarded as having 'dropped out' of the study and were

381 not included in primary analyses (see Supplemental Fig. 1). No participants dropped out after 
382 having completed any sessions, although several participants declined participation after 383 prescreening and before starting any sessions (see Supplemental Table 1).

384 At the beginning of each session, participants were told to think of the upcoming session 385 as "recording a journal" of their memories, rather than a conversation with the experimenter. 386 During each session, participants completed 15 trials, each consisting of listening to one $30 \mathrm{~s}$ 387 clip, then recalling one memory. These 15 trials were split into 3 blocks of 5 trials each

388 corresponding to childhood, adolescent, and early adulthood event prompts (order

389 counterbalanced across participants). During the familiar music condition, the developmental 390 time period of the release of each song clip matched the time period of the events (e.g., songs 391 released during the participant's childhood were paired with event prompts referring to the 392 participant's childhood). 


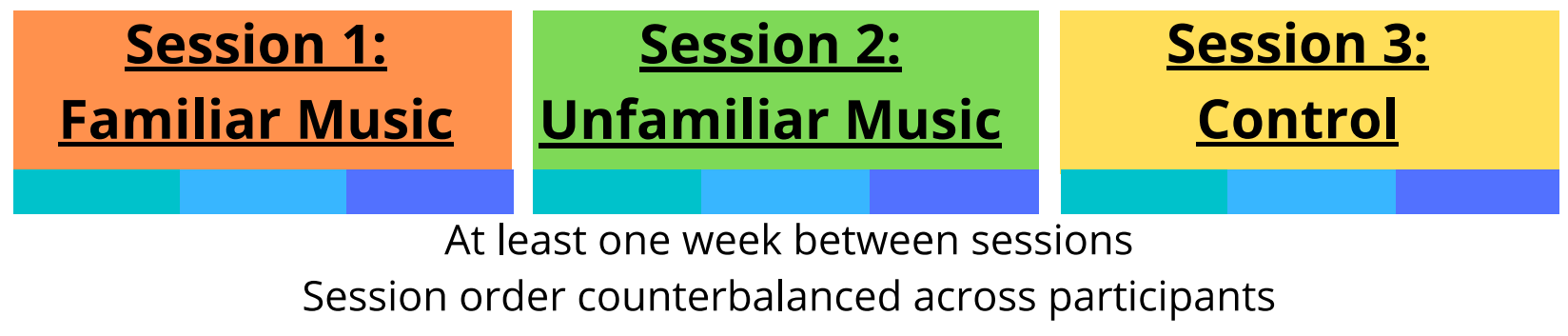

\section{Example Session}
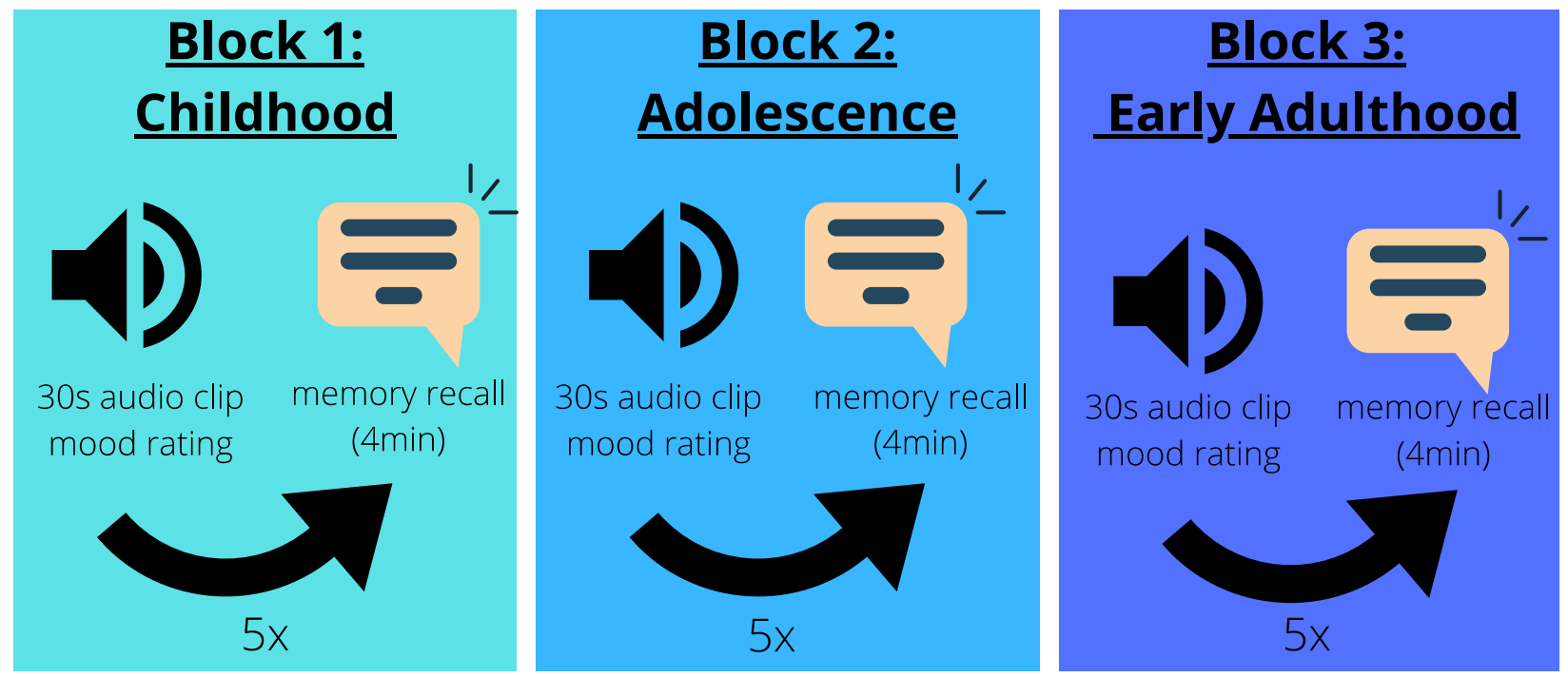

(block order counterbalanced across participants)

\section{0-90 minutes}

Figure 1: Study design. Top: Participants each took part in three sessions, in which they were exposed to either familiar music, unfamiliar music, or control non-music clips. After each clip, they were prompted to recall an autobiographical memory. Bottom: Schematic of an example session. Each session was split into 3 blocks, in which participants were prompted to recall events from either childhood, adolescence, or early adulthood. Each block consisted of 5 trials, in which participants first heard a music clip and then were prompted to recall an event.

Audio recordings were made of each session using Zoom. During each trial, participants were first instructed to relax and listen to a 30s audio clip. Participants were then asked to rate their mood based on the prompt "how did the clip you just heard made you feel?" on a numerical scale from 1-7 scale ( 1 = 'extremely negative', 4 = 'neutral', 7 = 'extremely positive'). Next, participants were prompted to elaborate on one of the events they had reported being able to 
406

407

408

409

410

411

412

413

414

415

429 Participants were thanked and had the opportunity to participate in a debriefing conversation in 430 which they were given time to discuss the study and any questions they had.

recall during the prescreening call. Within each time period, events were randomly assigned to each session. Following standard protocols for the Autobiographical Interview (Levine et al., 2002), participants were prompted to focus on a specific event, rather than general facts. If participants elaborated on events occurring in a different developmental time period than the one prompted, they were prompted again to focus on an event occurring during the prompted time period. If participants started to talk about events already elaborated upon for a previous prompt, they were asked to focus on a different event fitting the prompt description (see Supplemental Fig. 2). Participants were given up to 4 minutes to elaborate upon the prompt. If participants finished within this time, they were given a general probe for more details ("is there anything else you can remember about that event?"). No probes for specific types of details were given.

After 4 minutes total, participants were asked to rate the positivity and vividness of each memory on a numerical scale from 1-7. Following this, we assessed whether the audio clips also evoked spontaneous memories (i.e., MEAMs). Participants were asked whether the clip they heard during the trial brought any memories to mind spontaneously. If participants reported a spontaneous memory, they were then asked how closely related the prompted event was to the spontaneous memory on a numerical scale from 1 (completely different) to 5 (the same memory). Participants were not asked about the content of spontaneous memories.

At the end of the final session, participants listened to 10 s clips of both the familiar and unfamiliar music clips an additional time, and rated familiarity with each individual clip on a numerical scale from 1-5 (1 = 'not familiar at all', 5 = 'extremely familiar'). Participants also rated how much they listened to each clip during childhood (5-9 years of age), adolescence (14-18 years of age), early adulthood (20-25 years of age), and after age 25 on the same scale. 


\section{2}

433

434 this, experimenters ('transcribers') compared automatically generated (by Zoom) text transcripts

435 of each videocall to the audio recording and made any necessary corrections. Transcriptions

436 included all utterances made by both the participant and experimenter during the recall and

437 general probe periods. If a participant recalled more than one event following a probe, all events

438 were transcribed.

439

440

441

442

443

444

445

446

447

448

449

450

451

452

453

454

455

456

457

Each transcribed memory was scored by experimenters ('coders') using the

Autobiographical Interview guidelines developed by Levine et al. (2002). Consistent with prior work, details were coded as episodic (or 'internal') if they reflected occurrences, locations, perceptions, thoughts, or emotions specific to the primary event described in response to the probe (Wardell, Esposito, et al., 2020). Details not specific to the time and place of the primary event were coded as 'external'. Specifically, external details included semantic details (e.g., "We always went to the cabin in the summer") and episodic details that were not pertinent to the primary recalled episode. In particular, if more than one episode was recalled during a single prompt, the episode judged by the coding experimenter as most related to the prompt was considered the 'internal' or 'primary' episode, and any others were scored as 'external' episodes. Sum scores for total internal and external details were calculated for each memory prompt. Coders did not score any utterances by the experimenter running the session. Coders were not present at the experiment sessions they scored and were blind to the music condition. Study-specific manuals for transcribers and coders are available at https://github.com/pab2163/amfm_public.

For each participant, two coders initially scored each memory. If for that participant, reliability (as measured by the intraclass correlation coefficient; ICC2K) between coders was less than .9 , the coders examined discrepancies and re-scored memories, along with one additional coder. This process was then repeated, adding an additional coder each time, until 
458 reliability $\geq .9$ was reached. Once reliability $\geq .9$ was achieved, final scores for each memory

459 were calculated by averaging the ratings across all coders scoring that participant. While this

460 resulted in more total number of coders for some participants than others, it ensured a minimum

461 reliability of .9 for every participant. This procedure also ensured consistency in scoring across

462 all memories of a given participant, removing potential confounds that might be introduced by

463 varying the coders for different experimental sessions or blocks.

464

465 Inclusion Criteria

466 Only data from participants meeting all inclusion criteria from the prescreening call were

467 analyzed. All main analyses only included participants who completed all three music and

468 memory interview sessions. Although we planned additional analysis specifications including

469 participants who dropped out after completing only one or two sessions, no participants who

470 completed any sessions dropped out. Trials were included in primary analysis according to

471 Supplemental Fig. 2. Any trials where technological or other factors (other people, pets, etc.)

472 interrupted memory recall for more than 10 s were also excluded from analysis. If such

473 interruptions fell during music listening (prior to memory recall), we restarted the trial by playing

474 the music clip again from the beginning and included the trial in analyses. Under all trial-level

475 inclusion criteria, 6.8\% of all trials were excluded from analyses (see Supplemental Table 5). 


\begin{tabular}{|c|c|c|c|}
\hline Question & Analysis & Analysis Contingencies & Result \\
\hline $\begin{array}{l}\text { 1. Music familiarity } \\
\text { manipulation check: } \\
\text { Do participants rate } \\
\text { clips played in the } \\
\text { familiar condition as } \\
\text { more familiar than } \\
\text { clips played in the } \\
\text { unfamiliar condition? }\end{array}$ & $\begin{array}{l}\text { Bayesian multilevel } \\
\text { ordinal regression } \\
\text { model with } \\
\text { familiarity ratings } \\
\text { as outcome }\end{array}$ & $\begin{array}{l}\text { Planned analysis \#1 will only be } \\
\text { conducted if the manipulation is } \\
\text { successful, such that participants } \\
\text { rate clips in the familiar condition as } \\
\text { more familiar than clips played in the } \\
\text { unfamiliar condition on average. }\end{array}$ & $\begin{array}{l}\text { Participants rated clips in the familiar music } \\
\text { condition as more familiar than clips in the } \\
\text { unfamiliar music condition, indicating the } \\
\text { familiarity manipulation was successful (Fig. } \\
\text { 2A). }\end{array}$ \\
\hline $\begin{array}{l}\text { 2. Music exposure } \\
\text { timing manipulation } \\
\text { check: Do participants } \\
\text { report having listened } \\
\text { to familiar music clips } \\
\text { more within the time } \\
\text { period when they were } \\
\text { released (childhood, } \\
\text { adolescence, or early } \\
\text { adulthood) than other } \\
\text { times in life? }\end{array}$ & $\begin{array}{l}\text { Bayesian multilevel } \\
\text { logistic regression } \\
\text { model with } \\
\text { outcome indicating } \\
\text { whether } \\
\text { participants rate the } \\
\text { time period of song } \\
\text { release as the time } \\
\text { at which they } \\
\text { listened to it most }\end{array}$ & $\begin{array}{l}\text { No analyses will be contingent on } \\
\text { this. However, our interpretation of } \\
\text { any observed effects will be adjusted } \\
\text { based on whether this manipulation } \\
\text { check holds or not - namely if } \\
\text { participants report listening to songs } \\
\text { in the familiar music condition more } \\
\text { within the time period when they } \\
\text { were released than during other } \\
\text { times in life for }>80 \% \text { of songs in the } \\
\text { familiar music condition. }\end{array}$ & $\begin{array}{l}\text { Participants reported listening to clips most } \\
\text { during the time period of release roughly } \\
82 \% \text { of the time for songs released during } \\
\text { young adulthood, } 77 \% \text { of the time for songs } \\
\text { released during adolescence, and } 40 \% \text { of } \\
\text { the time for songs released during } \\
\text { childhood. This indicates that our } \\
\text { manipulation of music exposure timing was } \\
\text { often not specific to the time window of the } \\
\text { music release, especially for songs released } \\
\text { during childhood (Fig. } 2 B \text { ). }\end{array}$ \\
\hline $\begin{array}{l}\text { 3. Spontaneous } \\
\text { music-evoked recall } \\
\text { manipulation check }\end{array}$ & $\begin{array}{l}\text { Bayesian multilevel } \\
\text { logistic regression } \\
\text { model with } \\
\text { outcome indicating } \\
\text { whether clips evoke } \\
\text { spontaneous recall. }\end{array}$ & $\begin{array}{l}\text { No analyses will be contingent on } \\
\text { this. This analysis will inform } \\
\text { interpretations of whether our music } \\
\text { manipulation impacts spontaneous } \\
\text { autobiographical memory recall. }\end{array}$ & $\begin{array}{l}\text { Participants reported having spontaneous } \\
\text { memories most often in the familiar music } \\
\text { condition, less often in the non-music clips } \\
\text { condition, and least often in the unfamiliar } \\
\text { music condition (Fig. } 2 \text { C). }\end{array}$ \\
\hline $\begin{array}{l}\text { 4. Check for } \\
\text { coincidence between } \\
\text { spontaneous and } \\
\text { prompted recall }\end{array}$ & $\begin{array}{l}\text { Bayesian multilevel } \\
\text { logistic regression } \\
\text { model with } \\
\text { outcome indicating } \\
\text { whether } \\
\text { spontaneously } \\
\text { evoked and } \\
\text { prompted } \\
\text { memories coincide }\end{array}$ & $\begin{array}{l}\text { Planned specification curve analyses } \\
\text { will include a fork with an additional } \\
\text { covariate for coincidence if there is } \\
\text { an effect of music condition on } \\
\text { coincidence. }\end{array}$ & $\begin{array}{l}\text { Overall coincidence between the content of } \\
\text { spontaneous and prompted memories was } \\
\text { rare. However, such coincidence occurred } \\
\text { more often in the familiar music condition } \\
\text { compared to unfamiliar music and non- } \\
\text { music clips, so specification curve analyses } \\
\text { included forks with coincidence as a } \\
\text { covariate. }\end{array}$ \\
\hline
\end{tabular}

477 Table 2: Manipulation checks for music familiarity, music exposure timing, spontaneous

478 music-evoked recall, and coincidence between spontaneous and prompted recall will be

479 conducted first to inform primary planned analyses. 


\section{Manipulation checks}

Music familiarity manipulation check

To examine the effectiveness of our music familiarity manipulation, we tested whether participants reported being more familiar with the songs used in the familiar music condition compared to the unfamiliar music condition. Only data from the familiar music and unfamiliar music sessions was used in this analysis. Because music familiarity ratings are ordinal responses on a 5-point scale, we used a cumulative ordinal regression model with a probit link 490 function (Bürkner \& Vuorre, 2019). This model was fit with package default weakly informative 491 priors, and included participant-specific random effects of music condition. Effectiveness of the 492 music manipulation was examined through the fixed-effect term for music condition in a model 493 using the following R syntax:

familiarity_rating $\sim$ music_condition + (music_condition $/$ id $)$

We set criteria such that if $97.5 \%$ of draws from the posterior distribution for the music condition parameter had the same sign, this would be interpreted as evidence for an effect of music condition on familiarity ratings. If there was an effect of music condition, such that familiarity ratings are higher for songs in the familiar music condition, we would conduct planned

501 analysis \#1 (see Table 1 Question 1).

Music exposure timing manipulation check:

The goal of this analysis was to determine the degree to which participants' exposure to 505 songs in the familiar condition was highest during the time period of the song's release (i.e., 506 matching the time period of the corresponding event prompt). To that end, we tested whether 
507 participants rated listening to each song most during this time period, relative to several other

508 time periods in life. For each song in the familiar music condition, we compared each

509 participant's 1-5 ratings of exposure during childhood (5-9), adolescence (14-18), early

510 adulthood (20-25), and later in adulthood (25+). A song was coded as 'matching' if the

511 participant rated their exposure as highest (or tied for highest) during the time period of the

512 song's release, compared to the other time periods. We estimated the proportion of 'matching'

513 songs using a logistic regression model with random effects of time period of release

514 (childhood, adolescence, or early adulthood) for each participant:

515

516 matching time_period + (time_period / id)

517

We extracted posterior predictive distributions of the group-level proportion of matching

519 songs in each time period. We set decision criteria such that we would consider the song

520 exposure timing manipulation to have been successful if the median posterior estimate for the

521 proportion of songs matched was greater than 0.8 among songs released in each of the three

522 time periods (childhood, adolescence, early adulthood). No other analyses were conditional on

523 the results of this manipulation check, though our interpretations of any potential music effects

524 were based on whether this manipulation was successful.

Spontaneous music-evoked recall manipulation check

$527 \quad$ Although the primary focus of the current study was voluntary (prompted) recall, we also

528 assessed whether involuntary recall (i.e., memories that are spontaneously evoked by the clips)

529 differed as a function of music condition. Participants gave binary responses (yes/no) to indicate

530 whether each clip spontaneously evoked a memory. We estimated the proportion of clips

531 evoking spontaneous recall in each condition using a logistic regression model with random

532 effects of condition for each participant: 
534 spontaneous_recall music_condition + (music_condition / id)

535

From this model we examined the following contrasts: 1) likelihood of spontaneous recall

537 in the familiar music condition > unfamiliar music condition, and 2) likelihood of spontaneous

538 recall for both music conditions $>$ the no-music condition. If $97.5 \%$ of draws from the posterior

539 distribution had the same sign for either contrast, we interpreted this as evidence for an effect of 540 music condition on spontaneous recall.

541

542 Manipulation check for coincidence between spontaneous and prompted recall

543 It is possible that memories that are spontaneously evoked by a clip overlap to some

544 degree with the randomly selected event prompt. We expected such coincidence between

545 spontaneous and prompted memories to be rare. However, to ensure that this possibility did not

546 play a confounding role, we examined the proportion of total trials for which these memories

547 coincided. We defined 'coincide' as participants giving a rating $\geq 4$ (on a scale from $1-5$ ) for how

548 closely related the prompted and spontaneous memories were for a given trial. We used a

549 logistic regression model to estimate, for each condition, the proportion of clips evoking a

550 coinciding memory. This model included random intercepts and effects of condition for each

551 participant.

552

553 coincidence $~$ music_condition + (music_condition / id)

From this model we examined the following contrasts: 1) likelihood of coincidence in the

556 familiar music condition > unfamiliar music condition, and 2) likelihood of coincidence for both

557 music conditions > the no-music condition. If $97.5 \%$ of draws from the posterior distribution had

558 the same sign for either contrast, we interpreted this as evidence for an effect of music condition 
559 on coincidence between spontaneous and prompted memories. We planned that if there was

560 such an effect, then we would include an additional fork for all specification curve analyses in

561 which we added an additional trial-level binary covariate for degree of coincidence (see

562 Supplemental Table 6). This covariate was coded as 0 if participants did not report a

563 spontaneous memory or if coincidence did not occur (using the same coding as above) and

564 coded as 1 if coincidence did occur.

565

566

567

568

569

570

571 multilevel linear regression model to estimate effects of exposure to familiar music on retrieval

572 of both internal and external details, as well as the proportion of internal details (see Table 1

573 Question 1). In this model, we included both fixed and random (varying by participant) terms for

574 detail type, music condition, developmental time period, and the interactions of music condition

575 and developmental time period with detail type. While regressors for developmental time period

576 were included in all models to help explain variance, such effects were not the focus of the

577 current study (see Fig. 5). Detail type was effect-coded such that main effects of music condition

578 represented ANOVA-like grand mean differences in number of details recalled (averaging

579 across internal and external details). The model syntax in R was as follows:

580

581 num_details detail_type ${ }^{*}$ music_condition + detail_type ${ }^{*}$ time_period +

582 (detail_type*music_condition + detail_type*time_period / id) 
Our model structure allowed us to estimate effects of music exposure on both internal and external details individually, and with respect to each other. From the model, we examined

587 the following contrasts: 1) internal details in the familiar > unfamiliar music condition, 2) external 588 details in the familiar > unfamiliar music condition, 3) proportion of details that are internal (i.e., $589 \frac{\text { internal }}{\text { internal+external }}$ ) in the familiar > unfamiliar music condition, and 4) details in the familiar > 590 unfamiliar music condition, averaged across external and internal details. Effect estimates for all 591 contrasts were calculated through extracting 4000 draws from the model's posterior predictive 592 distribution for the linear predictor. Highest density intervals (HDI) were calculated for each 593 contrast. Such intervals are roughly analogous to confidence intervals (Turkkan \& Pham-Gia, 594 1993).

The primary analysis included data from the 75 participants meeting the main inclusion 596 criteria for the study, and included summed internal and external details, respectively, across 597 both the recall and general probe phases. Trials in which participants reported no memories in 598 response to probes were excluded from analysis, though trials for which participants reported 599 memories with no internal details (and $>0$ external details) were included (Supplemental Fig. 2). 600 Thus, all reported memories contributed to the analyses, irrespective of their content.

602 Specification curves: In addition to the primary analyses, we considered additional analyses 603 that were theoretically motivated. This allowed us to determine whether our observed results 604 were robust to different analysis decisions that were equally valid. To that end, we conducted 605 specification curve analysis to determine the robustness of observed results (Orben \& 606 Przybylski, 2019; Steegen et al., 2016). We reran the model described above under all possible 607 combinations of the analysis specifications detailed in Supplemental Table 6, resulting in a total 608 of 24 analysis specifications. For each contrast, we tested whether the median effect of the 609 specification curve significantly differed from that expected in the absence of a true effect 
610 through permutation testing. Specifically, we shuffled the music condition labels randomly for

611 each participant, then re-calculated the specification curve and the corresponding median effect

612 estimate 100 times (Simonsohn et al., 2015). This procedure tested the statistical significance of

613 the specification curve as a whole, and we considered any results for individual specifications

614 (other than the primary analyses) exploratory. We set an alpha level $\alpha=0.05$ as the criterion

615 for significance for these analyses. See specification curves at

616 https://pbloom.shinyapps.io/music_memory_specification_curves/.

617

618 2. Associations between ratings of song familiarity and memory retrieval

619 Primary analyses: We also used similar Bayesian multilevel linear regression models to those

620 outlined for analyses \#1 (see Table 1 Question 1) to estimate associations between participants'

621 ratings of familiarity for each song and retrieval of internal and external details following

622 exposure to that song (see Table 1 Question 2). We included random effects terms for

623 familiarity rating and time period (and their interactions with detail type) for each participant.

624 Familiarity rating was treated as a continuous variable, with effect coding for detail type and

625 dummy coding for time period (see Supplemental Table 8). The syntax will be as follows:

626

627 num_details detail_type*familiarity_rating + detail_type*time_period + (detail_type*

628 familiarity_rating + detail_type*time_period / id)

629

630

631

We examined the following four contrasts from the model: 1) the average expected

632 increase in internal details associated with a 1-unit increase in familiarity, 2) the average

633 expected increase in external details associated with a 1-unit increase in familiarity, 3) the

634 average expected increase in the proportion of details that are internal associated with a 1-unit 
635 increase in familiarity, and 4) the average increase in all details (averaged across internal and

636 external) associated with a 1-unit increase in familiarity.

638 3. Effects of music vs. non-music clips on memory retrieval

639 Primary analysis: To estimate effects of music on memory recall more generally (see Table 1

640 Question 3), we examined an additional 4 contrasts from the model described in planned

641 analysis \#1 (see Table 1 Question 1 and Supplemental Table 7). The contrasts we examined

642 here were: 1) internal details in both music conditions > no-music condition, 2) external details

643 in both music conditions > no-music condition, 3) the proportion of details that are internal in

644 both music conditions > no-music condition, and 4) all details in both music conditions > no-

645 music condition, averaged across external and internal details. Effect estimates were calculated

646 through draws from the model's posterior predictive distribution for the linear predictor as

647 previously detailed.

648

649 Corrections for multiple comparisons

650 To account for the multiple comparisons introduced by making inferences for several

651 contrasts from the same model, we implemented a modified Holm-Bonferroni procedure (Holm,

652 1979). For each model, contrasts were ordered from greatest to least by the proportion of

653 posterior draws with the same sign (a rough equivalent of frequentist confidence intervals;

654 Ludbrook, 2000). With a maximum family-wise error rate of $\alpha=0.05$, contrasts were interpreted

655 as showing evidence for an effect if a proportion greater than $1-\frac{\alpha / 2}{m}$ of posterior draws had the 656 same sign for each contrast, where $\mathrm{m}$ is initially the total number of contrasts tested (4 for each

657 model), then is reduced by 1 for each subsequently tested contrast (thereby relaxing the 658 criteria). If for any contrast, this multiple comparisons-corrected criterion was not met, we 
659 interpreted such a result as absence of consistent evidence for that contrast, and any following 660 contrasts.

661 We applied this correction for multiple comparisons to all models used in primary

662 analyses. However, such procedures were unnecessary, as no primary analyses met our

663 planned criteria for an effect even without such corrections. Because specification curve

664 analyses were considered in combination with the primary analysis, we did not apply additional 665 corrections for multiple comparisons to specification curves.

666 
Secondary Planned Analyses

669

\begin{tabular}{|c|c|c|c|}
\hline Question & Analysis & Interpretation & Result \\
\hline $\begin{array}{l}\text { 1. Effects of music condition on } \\
\text { mood: Is there an effect of music } \\
\text { condition on participant-rated } \\
\text { mood? }\end{array}$ & $\begin{array}{l}\text { Bayesian multilevel } \\
\text { ordinal regression } \\
\text { model with mood } \\
\text { ratings as outcome }\end{array}$ & $\begin{array}{l}\text { Results will inform the degree to } \\
\text { which our music manipulation } \\
\text { impacts affect. }\end{array}$ & $\begin{array}{l}\text { Familiar music clips evoked the } \\
\text { most positive affect compared to } \\
\text { unfamiliar music or non-music } \\
\text { clips. Unfamiliar clips also } \\
\text { evoked more positive affect } \\
\text { compared to non-music clips. }\end{array}$ \\
\hline $\begin{array}{l}\text { 2. Associations between mood } \\
\text { and retrieval of internal and } \\
\text { external details: Is participant- } \\
\text { rated mood associated with } \\
\text { voluntary retrieval of internal } \\
\text { details, external details, or the } \\
\text { proportion of internal details? }\end{array}$ & $\begin{array}{l}\text { Bayesian multilevel } \\
\text { linear regression } \\
\text { model with number } \\
\text { of details as } \\
\text { outcome, contrasts } \\
\text { for a } 1 \text {-unit } \\
\text { increase in mood } \\
\text { rating }\end{array}$ & $\begin{array}{l}\text { Results will inform } \\
\text { interpretations of whether music } \\
\text { effects on memory retrieval may } \\
\text { be related to changes in mood. }\end{array}$ & $\begin{array}{l}\text { We did not find associations } \\
\text { between affect and retrieval of } \\
\text { internal or external details. }\end{array}$ \\
\hline $\begin{array}{l}\text { 3. Associations between } \\
\text { spontaneous recall and } \\
\text { voluntary retrieval of internal } \\
\text { and external details: Is the } \\
\text { occurrence of a spontaneous } \\
\text { memory associated with } \\
\text { subsequent voluntary retrieval of } \\
\text { internal details, external details, } \\
\text { or the proportion of internal } \\
\text { details? }\end{array}$ & $\begin{array}{l}\text { Bayesian multilevel } \\
\text { linear regression } \\
\text { model with number } \\
\text { of details as } \\
\text { outcome, including } \\
\text { only participants } \\
\text { who reported } \\
\text { spontaneous recall } \\
\text { on at least one trial }\end{array}$ & $\begin{array}{l}\text { Results will inform whether } \\
\text { spontaneous recall is associated } \\
\text { with subsequent enhanced } \\
\text { deliberate recall. If so, this might } \\
\text { indicate a potential mechanism } \\
\text { by which music could boost } \\
\text { voluntary recall. }\end{array}$ & $\begin{array}{l}\text { We did not find associations } \\
\text { between spontaneous recall and } \\
\text { voluntary (prompted) recall of } \\
\text { internal or external details. }\end{array}$ \\
\hline $\begin{array}{l}\text { 4. Associations between self- } \\
\text { reported music exposure } \\
\text { during the time period of music } \\
\text { release and voluntary memory } \\
\text { retrieval: Is higher self-reported } \\
\text { exposure during the time period } \\
\text { of music release (vs. during } \\
\text { different time periods) associated } \\
\text { with retrieval of internal details, } \\
\text { external details, or the proportion } \\
\text { of internal details? }\end{array}$ & $\begin{array}{l}\text { Bayesian multilevel } \\
\text { linear regression } \\
\text { model with number } \\
\text { of details as } \\
\text { outcome, including } \\
\text { only trials from the } \\
\text { familiar music } \\
\text { condition }\end{array}$ & $\begin{array}{l}\text { Results will inform whether } \\
\text { exposure to music during the } \\
\text { time period of music release } \\
\text { (versus other times in life) is } \\
\text { associated with retrieval of } \\
\text { memories from the same time } \\
\text { period. Such an association } \\
\text { might suggest temporally } \\
\text { specific effects of music on } \\
\text { memory recall. }\end{array}$ & $\begin{array}{l}\text { While preregistered analyses } \\
\text { found an association between } \\
\text { exposure during the time period } \\
\text { of release and prompted recall of } \\
\text { internal details, such analyses } \\
\text { were likely confounded by the } \\
\text { time periods of the prompted } \\
\text { events. In follow-up analyses } \\
\text { controlling for the time period of } \\
\text { events, we did not find } \\
\text { associations between exposure } \\
\text { during the time period of music } \\
\text { release and recall of internal or } \\
\text { external details (see } \\
\text { Supplemental Results). }\end{array}$ \\
\hline
\end{tabular}

670 Table 3: Questions, analysis methods, interpretations, and results, for secondary planned analyses.

671 
672

673

674

675

676

677

678

679

680

681

682

683

684

685

686

687

688

689

690

691

692

693

694

695

696

Effects of music condition on mood

Although our music manipulation was not designed to affect participants' mood, we analyzed mood as a function of music condition (Jakubowski et al., 2018; Nineuil et al., 2020;

Schulkind et al., 1999). Mood (affect) ratings were ordinal responses on a 7-point scale, so we used a cumulative ordinal regression model (as we proposed for the music familiarity manipulation check). We estimated effects of familiar relative to unfamiliar music clips, and music relative to non-music clips, on self-reported mood. This model included a regressor for developmental time period to help the model explain more variance. This model also had participant-specific random effects of music condition and time period as follows:

mood $\sim$ music_condition + time_period + (music_condition + time_period / id $)$

From this model we examined the following contrasts: 1) mood ratings in the familiar music condition > unfamiliar music condition, and 2) mood ratings in both music conditions $>$ the no-music condition. If $97.5 \%$ of draws from the posterior distribution had the same sign for either contrast, we interpreted this as evidence for an effect of music condition on mood.

\section{Associations between mood and memory retrieval}

To ask whether mood and remote memory retrieval were associated, we will model both internal and external details as a function of mood (Palombo et al., 2020; Sheldon et al., 2020; Sheldon \& Donahue, 2017; Simpson \& Sheldon, 2019; Wardell, Madan, et al., 2020). Detail type was effect-coded such that the main effect of mood represented the mean association of mood with retrieval averaged across internal and external details. Number of details and mood were treated as continuous variables, and mood was z-scored within participants. The model syntax in $\mathrm{R}$ included participant-level random effects for all terms as follows: 
698

699

700

701

702

703

704

705

706

707

708

709

710

711

712

713

714

715

716

717 From this model we examined the following contrasts: 1) number of internal details recalled in

718 trials with spontaneous recall > trials without spontaneous recall, 2) number of external details

719 recalled in trials with spontaneous recall > trials without spontaneous recall, 3) the total number

720 of details (across internal and external) in trials with spontaneous recall $>$ trials without

721 spontaneous recall, and 4) the proportion of recalled details that are internal in trials with

722 spontaneous recall $>$ trials without spontaneous recall. 
724 Associations between self-reported music exposure during the time period of music release and

725 voluntary memory retrieval

726 For the familiar music condition only, we also asked whether self-reported music

727 exposure during the time period of the music's release (childhood, adolescence, or early

728 adulthood) was associated with deliberate recall of memories from that same time period. To

729 accomplish this, we constructed a Bayesian multilevel linear regression to estimate associations

730 between reported exposure to music clips and deliberate recall of internal or external details.

731 The preregistered model had terms for both music exposure during the time period of the

732 music's release (music_exposure_matching) and average music exposure during all other time

733 periods (music_exposure_nonmatching). The preregistered model included both music

734 exposure terms, detail type (internal vs. external), and interactions of the music exposure terms 735 with detail type, with participant-varying random effects for all parameters.

736

737 Num_details music_exposure_matching ${ }^{*}$ detail_type +

738 music_exposure_nonmatching ${ }^{\star}$ detail_type + (music_exposure_matching ${ }^{*}$ detail_type +

739 music_exposure_nonmatching ${ }^{*}$ detail_type / id)

740

741 After data collection, we realized that associations of time-windowed music exposure in

742 the preregistered model were likely confounded by the developmental time windows of the

743 prompted event memories. Within the familiar music condition, the time period of the event

744 prompt was matched to the time period of song release, and time-windowed music exposure

745 was higher for songs released in adolescence and young adulthood compared to childhood

746 (Supplemental Fig. 13). Thus, effects of the time period of the recalled events-more internal

747 details for adolescent and young adulthood memories vs. those from childhood—may have

748 driven apparent effects of music exposure in the preregistered model. To explore this possibility, 
749 we fit an additional (not preregistered) model with added covariates for the time period of the

750 events as follows:

751

752 num_details music_exposure_matching ${ }^{*}$ detail_type +

753 music_exposure_nonmatching ${ }^{\star}$ detail_type + time_period ${ }^{*} d e t a i l t y p e+$

754 (music_exposure_matching ${ }^{\star} d e t a i l$ type + music_exposure_nonmatching ${ }^{\star}$ detail_type +

755 time_period*detail_type / id)

756

From these models we examined the following contrasts: 1) the average expected

758 increase in internal details associated with a 1-unit increase in music exposure in the matching

759 time period, 2) the average expected increase in external details associated with a 1-unit

760 increase in music exposure in the matching time period, 3) the average expected increase in

761 internal details associated with a 1-unit increase in music exposure in the non-matching time

762 periods, and 4) the average expected increase in external details associated with a 1-unit

763 increase in music exposure in the non-matching time periods. Multiple comparisons corrections

764 were applied across contrasts (see Corrections for Multiple Comparisons). See Supplemental

765 Results and Supplemental Fig. 10 for all results of this analysis.

766

767 Model-fitting

768 We fit all models using Hamiltonian Monte Carlo No-U-Turn sampling as implemented by

769 the brms package in the R computing environment (Bürkner, 2019). We chose to use fully

770 Bayesian estimation for all models to improve estimation of hierarchical regression models with

771 many parameters, as well as to address the practical concern that maximum likelihood-based

772 approaches are often prone to model convergence issues or underestimation of coefficient

773 uncertainty (Chung et al., 2015). All linear models were fit using weakly informative priors,

774 namely package-default student's t distributions centered at 0 with 3 degrees of freedom and a 
775 scale parameter of 10 (units are standard deviations of the predictor variable) for both fixed

776 effects and the standard deviation of participant-level random effect distributions (priors for

777 standard deviations were censored to only include values 0 and above). Additionally, a

778 package-default LJK prior with shape $\eta=1$ was used for the covariance matrix of participant-

779 level coefficients. For all models, we fit 4 chains of 2000 sampling iterations (1000 warmup)

780 each for a total of 4000 post-warmup samples. In cases where the tail effective sample size was

781 low (as indicated by Stan warning messages), we added 1000 more sampling iterations for each

782 chain until sufficient tail effective sample size was achieved. For all primary analysis models, the

$783 \hat{R}$ statistic for all fixed effects was below a threshold of 1.1 (Gelman et al., 2013). We computed

784 full posterior distributions for all contrasts of interest, and plotted these along with corresponding

785 highest density intervals for each primary analysis (Kruschke, 2021; van de Schoot et al., 2021).

786 Extraction and transformation of posterior draws after models were fit was done using the

787 tidybayes package and the tidyverse collection of packages in R (Kay, 2022; Wickham et al., 788 2019). All results figures were created using ggplot2.

789

\section{Exploratory Analyses}

Differences in prompted recall as a function of age at the time of the prompted event

794 prompted recall of internal or external details differed as a function of age at the time of the

795 prompted event. This served as an additional (not preregistered) manipulation check, given that

796 autobiographical memories tend to be less detailed for childhood events (Bauer, 2012).

797 Between each of the time periods (childhood, adolescence, or young adulthood), we calculated

798 posterior contrasts for differences in internal details, external details, all details (the sum of

799 internal + external), and the proportion of details that were internal. Multiple comparisons 
800

801

802

803

804

805

806

807

808

809

810

811

812

813

814

815

816

817

note several small changes from the registered protocol. First, we used an additional

821 recruitment method of paper flyers posted in several locations in New York City, and we did not

822 recruit any participants through shared institutional participant lists. In addition, while the

823 preregistered protocol stated that we would play participants a sample audio clip at the end of

824 the prescreening session, we played this audio at the beginning of each study session to ensure

825 that audio quality was sufficient for each call. 
Although preregistered methods stated that participants would be given 4 minutes to

827 recall a memory in response to each prompt, in practice it was difficult to interrupt participants if

828 they were continuing to recall a memory beyond the designated time. This was particularly true

829 because participants could not always hear on Zoom if an experimenter interjected while they

830 were simultaneously speaking. Thus, for some trials (10.3\%), recall continued after 4 minutes

831 before the experimenter was able to move on to the next item. Experimenters worked to be as

832 consistent as possible for each participant in moving to the next follow-up question as soon as

833 possible after 4 minutes of recall had elapsed.

834 Preregistered methods also stated that members of the research team correcting

835 automatically generated text transcripts ('transcribers') using the Zoom audio would not be

836 those conducting the corresponding study sessions. However, some Zoom transcripts (25

837 participants) were corrected by the same person who conducted the session, such that

838 transcribers in these cases were aware of the music condition for the text transcripts they

839 corrected. In addition, even when transcribers were not correcting transcripts for sessions they

840 ran themselves, they could have been aware of the condition because the recordings and text

841 transcripts contained the audio of the clips and corresponding text (i.e., the song lyrics or

842 dialogue from non-music clips; transcribers always removed this information from transcripts so

843 that coders would not see it). It is unlikely that this could have been a potential source of bias,

844 as transcribers did not make decisions about how memories were coded and were always

845 distinct from coders making such decisions for each participant.

846 Lastly, with the permission of the journal editor, we added one questionnaire item at the

847 end of the final study session assessing participants' liking of each music clip on a numerical

848 scale from 1-5 (see Supplemental Fig. 3). Overall, we believe that the deviations from the

849 preregistered protocol were minor and did not substantially impact the rigor or results of the

850 study. 
Results

A

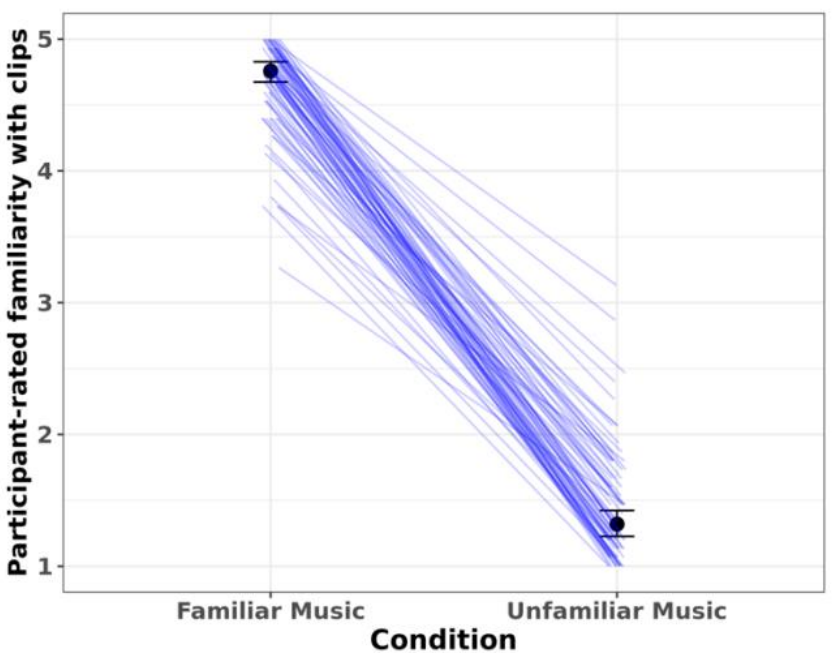

C

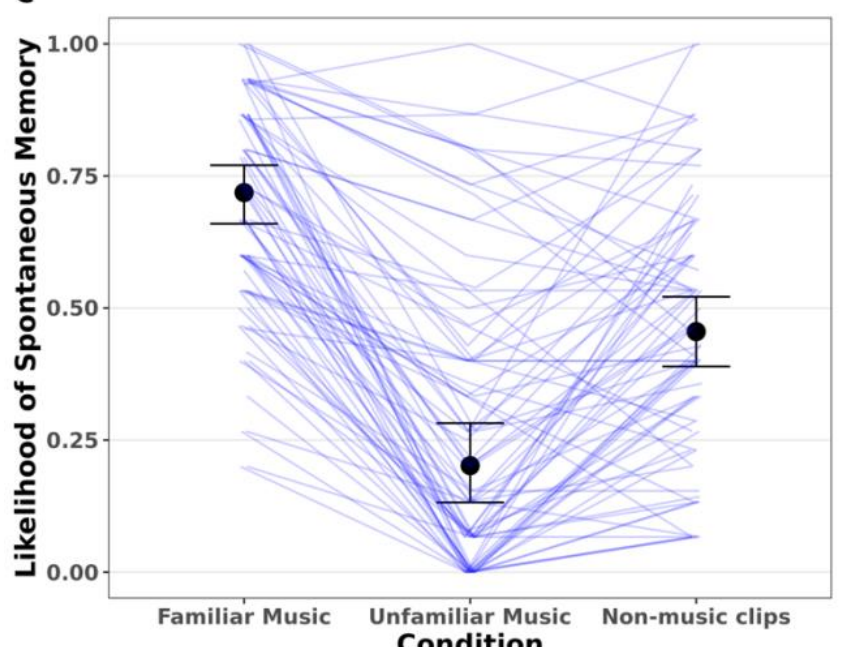

\section{Manipulation Checks \& Preliminary Planned Analyses}
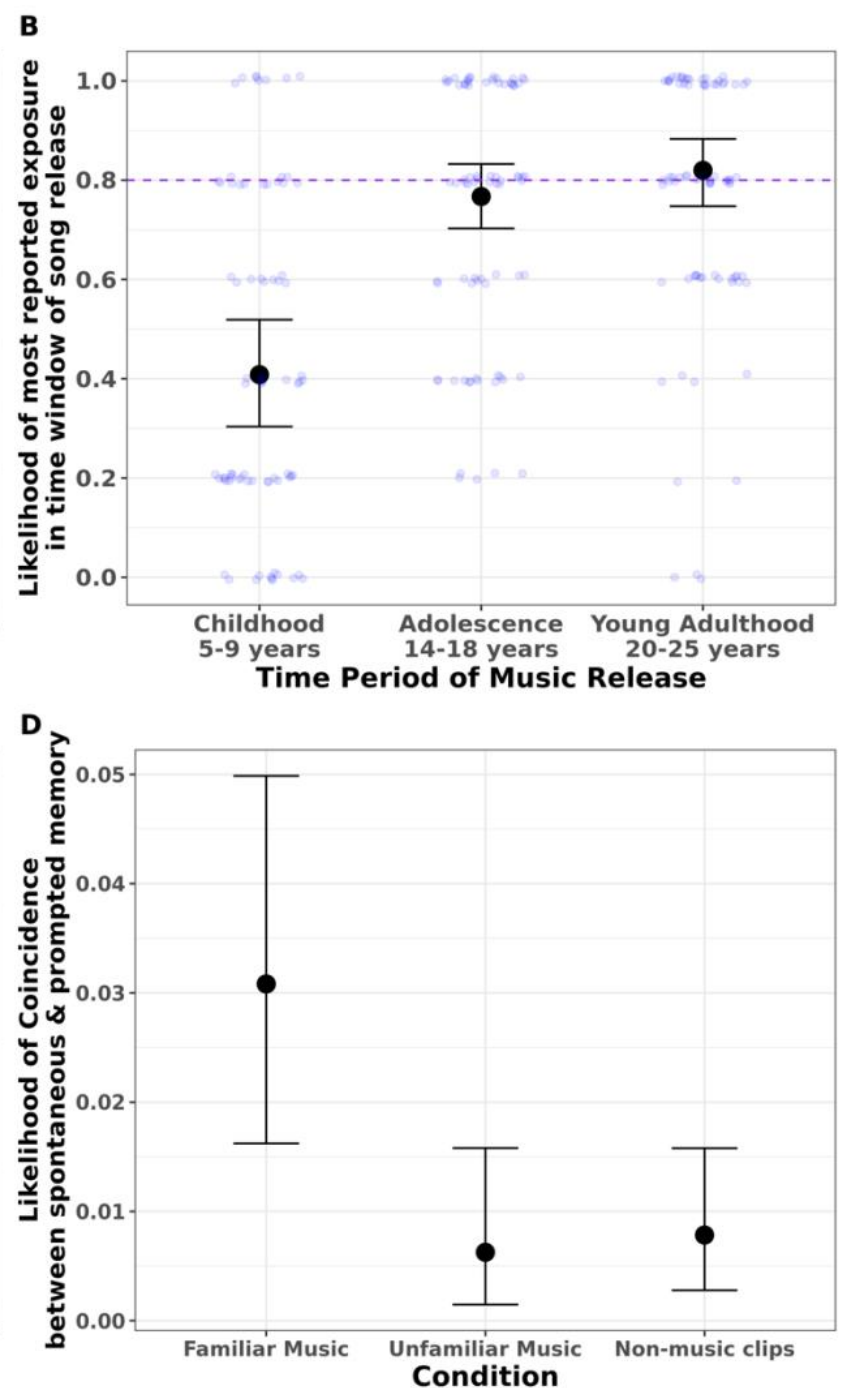

Figure 2: Manipulation checks and preliminary analyses (see Table 2). A: Song familiarity manipulation check. Participant-reported familiarity ( $y$-axis) with music clips selected to be familiar and unfamiliar. Note: while familiarity was treated as an ordinal variable in the model, it is plotted as a continuous variable here for ease of visualization. B: Likelihood of highest selfreported music clip exposure during the window of each song's release. Y-axis shows the estimated proportion of trials where participants reported the highest (or tied for highest) exposure to each song clip during the developmental window of the song's release (from the options of ages 5-9, 14-18, 20-25, or 26-present). The dashed horizontal line at 0.8 represents the preregistered study criterion for successful manipulation of the time window of music exposure. C: Likelihood of participants reporting that a spontaneous memory was evoked during listening of sound clips in each condition. D: Likelihood of coincidence between spontaneous memories and prompted memories in each condition. Coincidence was defined by participants giving a rating $\geq 4$ (on a 1-5 numerical scale) for how similar the spontaneous and prompted memories were for each given trial. For all panels, black points and error bars represent grouplevel model estimates and $95 \%$ posterior intervals, and blue points or lines are summaries 
872 (average familiarity in panel A, proportions in panels B \& C) of each individual participant's raw 873 data.

\section{Music Familiarity Manipulation Check}

A Bayesian multilevel cumulative ordinal regression model indicated that participant-

878 reported familiarity with music clips was higher in the familiar music condition compared to the 879 unfamiliar music condition ( $\beta=3.53,95 \%$ HDI [3.26, 3.83]). Further, all individual participants 880 reported numerically higher average familiarity in the familiar music condition compared to the 881 unfamiliar condition (Fig. 2A). We interpret this as a successful manipulation of music familiarity 882 (see Table 1 Q1).

883

Music Exposure Timing Manipulation Check

885

Using a Bayesian multilevel logistic regression model, we estimated the proportion of clips in the familiar music condition for which participants reported the highest (or tied for

887 highest) exposure during the time window of the song's release (among the options of childhood

888 [ages 5-9], adolescence [ages 14-18], young adulthood [ages 20-25], and 26-present) (Fig. 2B).

889 Although participants reported highest exposure during the time window of release for the 890 majority of songs released during their adolescence (Median proportion $=0.77,95 \%$ HDI $[0.70$, 8910.83 ) and young adulthood (Median proportion $=0.82,95 \% \mathrm{HDI}[0.75,0.88]$ ), this was true less 892 often for songs released during their childhood (Median proportion $=0.40,95 \% \mathrm{HDI}[0.30,0.52$ ). 893 Based on the criteria of a 0.8 likelihood of highest reported exposure during the time window of 894 release, our music exposure timing manipulation did not succeed in temporal specificity (see 895 Table 1 Q2). Thus, any effects of familiar music on memory cannot be ascribed to temporal 896 matching between prompted events and the developmental timing of the release of the songs. 


\section{Spontaneous music-evoked recall}

Using a Bayesian multilevel logistic regression model, we estimated the proportion of trials in each condition for which participants reported a spontaneous memory coming to mind while listening to the clip (Fig 2C). We found an effect of music familiarity on spontaneous recall, such that participants reported more spontaneous memories in the familiar music condition compared to both the unfamiliar music condition $(\beta=2.31,95 \%$ HDI $[1.92,2.75])$ and the nonmusic clips condition $(\beta=1.11,95 \% \mathrm{HDI}[0.85,1.38])$. In addition, participants reported more spontaneous memories in the non-music clips condition compared to the unfamiliar music condition $(\beta=1.20,95 \% \mathrm{HDI}[0.81,1.63])$. This latter effect was not expected, and we explore reasons for why unfamiliar music may have evoked the fewest spontaneous memories in the Discussion.

\section{Coincidence between spontaneous and prompted recall}

We used a Bayesian multilevel logistic regression model to estimate the proportion of all trials where participants reported a high degree of coincidence ( $\geq 4$ on a numerical scale from 1 5) between prompted and spontaneous memories in each condition. Although such coincidence was rare overall (generally fewer than $5 \%$ of trials; Fig. 2D), participants reported coincidence more often during the familiar music condition compared to either the unfamiliar music $(\beta=1.61$, 95\% HDI $[0.55,2.89])$ or non-music clips ( $\beta=1.37,95 \%$ HDI $[0.70,2.33])$. There were no differences in likelihood of coincidence between the unfamiliar music condition and non-music clips $(\beta=-0.20,95 \%$ HDI $[-1.61,0.96])$. Thus, we included specifications in our specification curves for primary planned analyses with an additional covariate for coincidence (see Supplemental Table 6). 


\section{A}
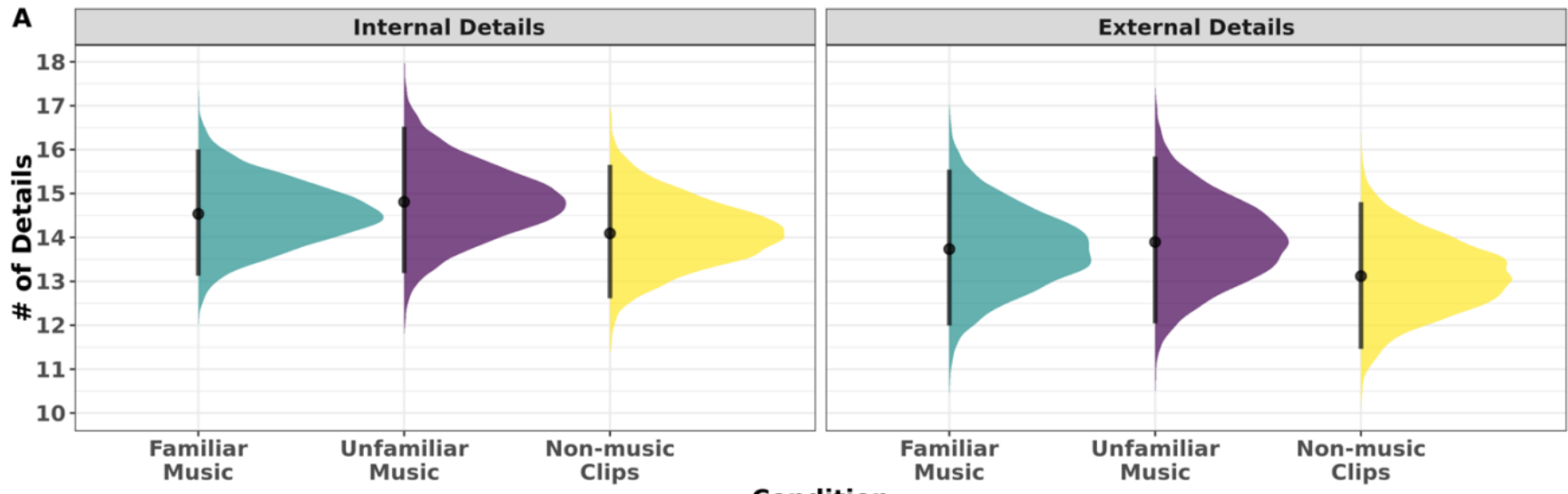

B

924

925

926

927

928

929

930

931

932

933

934

935

936

937

938

939

940

941

942

943
C

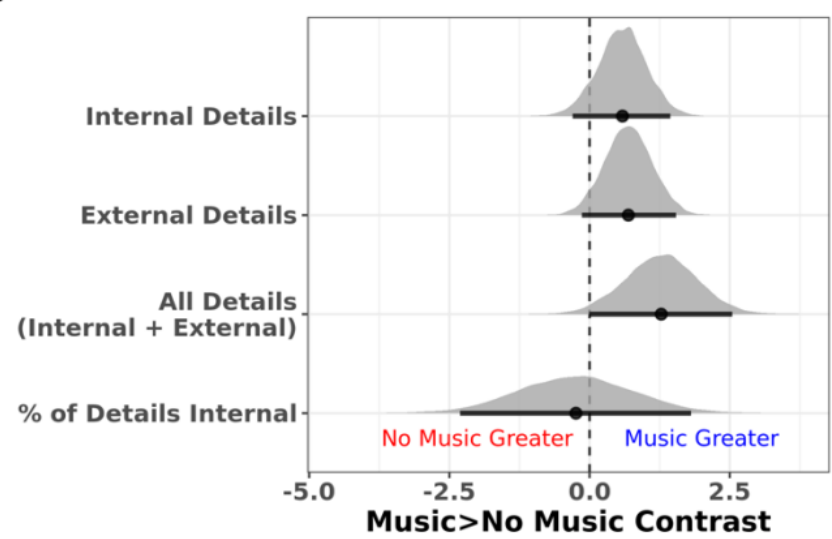

Figure 3: Effects of music manipulation on deliberate recall. Overall, primary analyses found no effects of familiar > unfamiliar music (see Table 1 Q1) or all music > non-music clips (see Table 1 Q3) under preregistered criteria, as 95\% posterior intervals for all contrasts included 0 . A: Model predictions for mean internal (left) and external (right) details recalled in each condition. Shaded distributions are posterior predictive distributions for mean details, and black points and error bars represent posterior medians and 95\% intervals. B: Posterior distributions for the familiar music > unfamiliar music contrast, representing differences in mean recall between those two conditions. Shaded distributions represent all posterior contrast samples, and error bars represent $95 \%$ intervals. C: Posterior distributions for the all music > non-music clips contrast, representing differences in mean recall between those two conditions. As all $95 \%$ intervals included 0, multiple comparisons-corrected intervals are not displayed.

\section{Effects of familiar vs. unfamiliar music exposure on prompted memory recall} We found no effects of familiar versus unfamiliar music exposure on prompted memory recall under preregistered decision criteria (Fig. 3A-B). Specifically, a Bayesian multilevel regression model did not find differences between the familiar and unfamiliar music conditions in internal details (Familiar > unfamiliar estimate $=-0.27,95 \%$ HDI $[-1.27,0.82]$ ), external details 
944 (Familiar > unfamiliar estimate $=-0.17,95 \%$ HDI $[-1.34,1.00]$ ), all details (the sum of internal +

945 external) combined (Familiar > unfamiliar estimate $=-0.44,95 \%$ HDI $[-2.11,1.16]$ ), or the

946 percentage of details that were internal (Familiar > unfamiliar estimate $=-0.17,95 \%$ HDI [-2.90,

947 2.40]). Specification curves also found no evidence for effects of familiar versus unfamiliar

948 music on prompted recall (see

949 https://pbloom.shinyapps.io/music_memory_specification_curves/). Additional visualizations

950 illustrating summaries of the raw data and between-participant heterogeneity in effects of

951 familiar music can be found in Supplemental Figures 6 \& 7.

952

Associations between ratings of song familiarity and prompted memory recall

We found no associations between participant-reported familiarity with music clips and

955 prompted memory recall under preregistered decision criteria (Fig. 4). Specifically, a Bayesian

956 multilevel linear regression did not find associations between music clip familiarity and internal

957 details $(\beta=-0.02,95 \% \mathrm{HDI}[-0.30,0.24])$, external details $(\beta=-0.04,95 \% \mathrm{HDI}[-0.33,0.25])$, all

958 details (sum of internal + external) combined $(\beta=-0.07,95 \%$ HDI $[-0.47,0.33])$, or the

959 percentage of details that were internal $(\beta=0.04,95 \%$ HDI $[-0.63,0.73])$. Specification curves

960 also found no such associations (see

961 https://pbloom.shinyapps.io/music memory specification curves/).

962
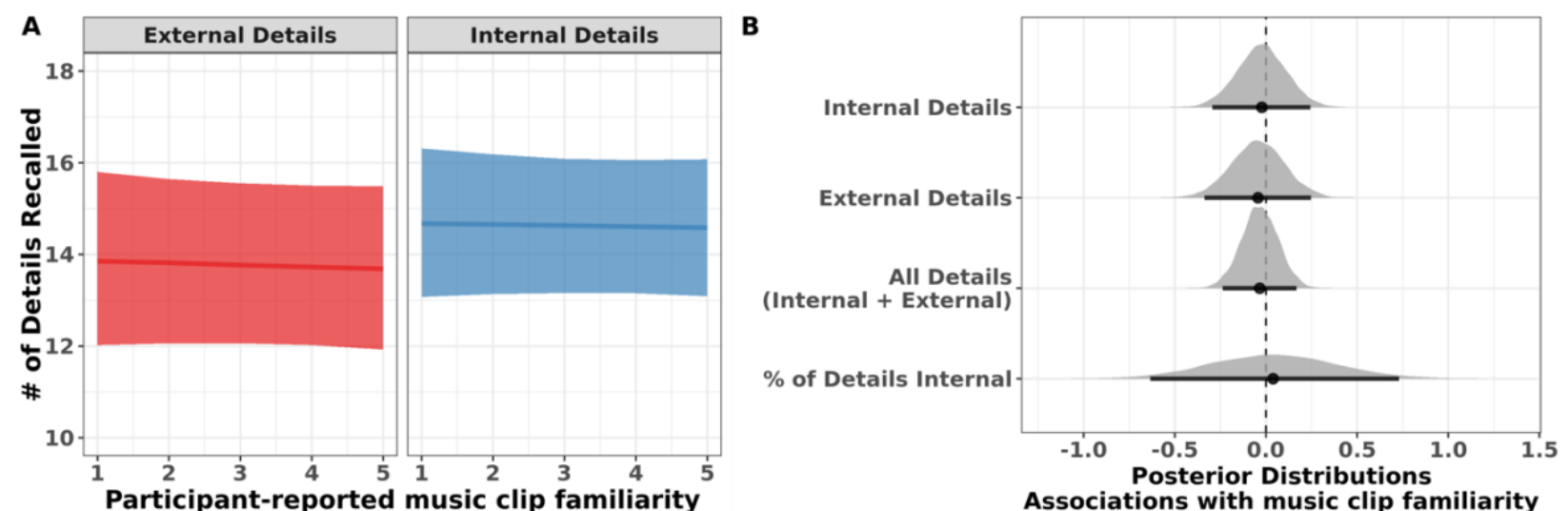
964 Figure 4: Associations between participant-reported music clip familiarity and deliberate recall.

965

966

967

968

969

970

971

972

973

974

975

976

977

978

979

980

981

982

983

984

985

986

987

988

989

990

991

992

993

994

995

A: Model-predicted mean details recalled as a function of participant-reported familiarity (on a numerical scale from 1-5) with each music clip. This analysis included only clips from the familiar and unfamiliar music conditions. Lines represent median posterior predictive estimates for average internal (left) and external (right) details, and shaded regions represent 95\% posterior intervals. B: Posterior distributions for estimated associations between memory detail type and participant-reported familiarity. For Internal Details, External Details, and All Details, posterior estimates represent the change in number of details recalled with a 1 -unit (on a numerical scale from 1-5) increase in clip familiarity. For \% of Details Internal, posterior estimates represent the change, with a 1-unit increase in clip familiarity, in the percentage of recalled details that are internal. As all 95\% intervals included 0, multiple comparisons-corrected intervals are not displayed.

\section{Effects of music vs. non-music clips on prompted memory recall}

Primary analysis did not find any robust effects of exposure to music (both familiar and unfamiliar combined) versus non-music clips on prompted recall under preregistered decision criteria (Fig. 3A \& C), although some weak evidence was observed. Specifically, a Bayesian multilevel regression model did not find differences between the music and non-music clips conditions in internal details (Music $>$ no-music estimate $=0.58,95 \%$ HDI $[-0.29,1.45]$ ), external details (Music $>$ no-music estimate $=0.69,95 \%$ HDI $[-0.16,1.52]$ ), all details (the sum of internal + external) combined (Music > no-music estimate=1.27, 95\% HDI [-0.01, 2.53]), or the percentage of details that were internal (Music $>$ no-music estimate $=-0.25,95 \% \mathrm{HDI}[-2.31$, 1.80]). For external details and all details combined, however, the 95\% HDIs (not adjusted for multiple comparisons) barely overlapped 0 , with most posterior draws indicating that more details were recalled in the music compared to no-music condition.

Specification curves allowed us to examine whether effects were present using different analysis choices. However, no specification curves found strong evidence for effects of music versus non-music clips on prompted recall (see https://pbloom.shinyapps.io/music_memory_specification_curves/). While the permutation test for the specification curve for differences in all details (sum of internal + external) resulted in $p=$ .05 , this $p$-value did not strictly meet the preregistered $p<.05$ criteria, and only 3 out of 24 
996 individual specifications (not including the primary analysis) indicated an effect such that the

$99795 \%$ highest density interval excluded 0 . Because the permutation test of the specification curve

998 was limited to 100 resampling iterations for computational feasibility, and not adjusted for

999 multiple comparisons (though decision criteria for primary analyses were adjusted for multiple

1000 comparisons), the result of the specification curve should not be over-interpreted as strong

1001 evidence of an effect. The combination of the primary analysis and specification curve indicate

1002 that the evidence for an effect of music exposure on prompted recall is not robust, and at best

1003 mixed.

1004

1005

\section{Secondary Planned Analyses}

1006

1007

1008

Effects of music manipulation on clip-evoked affect

We used a Bayesian multilevel cumulative ordinal regression model to estimate effects

1009 of the music manipulation on affect (rated on a 1 [most negative] to 7 [most positive] numerical

1010 scale) evoked by the sound clips (Supplemental Fig. 9A). We found differences between all

1011 conditions, such that evoked affect was more positive on average for familiar music clips

1012 compared to both unfamiliar music $(\beta=1.23,95 \% \mathrm{HDI}[1.06,1.38])$ and non-music clips $(\beta=1.69$,

$101395 \% \mathrm{HDI}[1.52,1.87])$. Evoked affect was also more positive on average for unfamiliar music

1014 clips compared to the non-music clips ( $\beta=0.46,95 \% \mathrm{HDI}[0.30,0.64])$.

1015

1016

1017

Associations between clip-evoked affect and prompted memory recall

1018

We found no associations between clip-evoked affect and prompted memory recall

1019 (Supplemental Fig. 9B-C). Specifically, a Bayesian multilevel regression did not find

1020 associations between clip-evoked affect and internal details ( $\beta=0.01,95 \%$ HDI $[-0.23,0.25])$,

1021 external details $(\beta=0.11,95 \% \mathrm{HDI}[-0.09,0.32])$, all details (the sum of internal + external) 
1022 combined $(\beta=0.06,95 \% \mathrm{HDI}[-0.10,0.22])$, or the percentage of details that were internal $(\beta=-$

$1023 \quad 0.18,95 \%$ HDI $[-0.74,0.37])$.

1024

1025

Associations between spontaneous and prompted memory recall

1026

We found no differences in prompted memory recall as a function of whether a

1027 spontaneous memory occurred during listening to the sound clip on the same trial

1028 (Supplemental Fig. 11). Specifically, a Bayesian multilevel regression did not find differences in 1029 internal details $(\beta=-0.15,95 \%$ HDI $[-0.80,0.46])$, external details $(\beta=0.56,95 \%$ HDI $[-1.18$,

$10300.08]$ ), all details (the sum of internal + external) combined ( $\beta=-0.71,95 \%$ HDI $[-1.54,0.31]$ ), or

1031 the percentage of details that were internal $(\beta=0.78,95 \% \mathrm{HDI}[-0.77,2.36])$ as a function of

1032 whether a spontaneous memory had occurred.

1033

1034

1035

1036

1037

Exploratory Analysis Results

1038

1039 
A

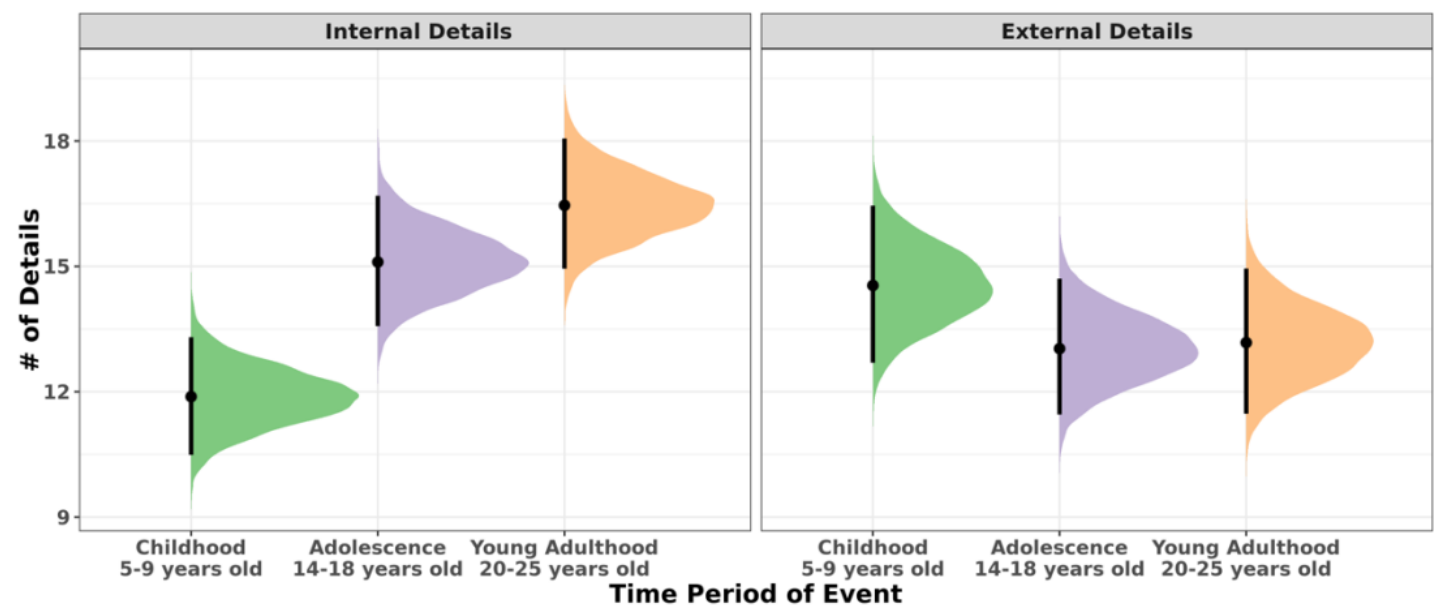

B

Contrast Posterior Distributions

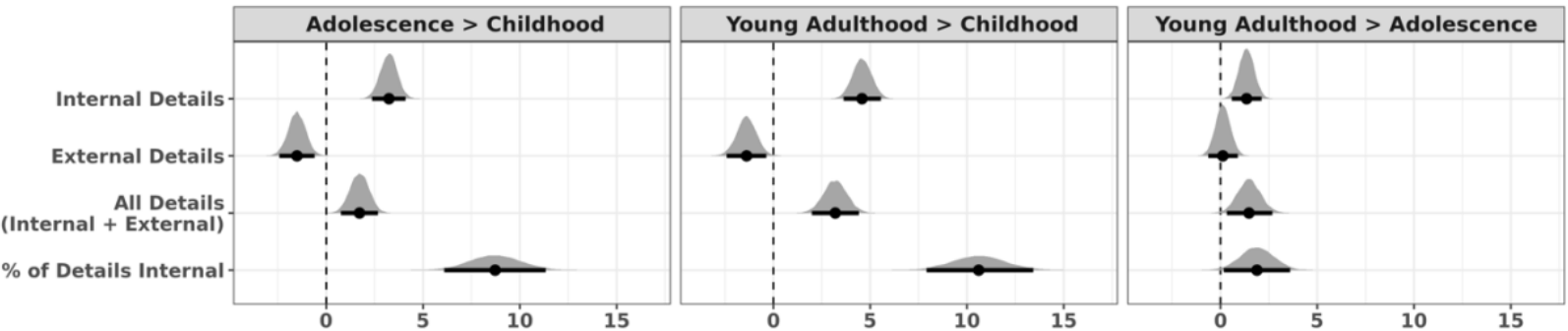

1040

1041

1042

1043

1044

1045

1046

1047

1048

1049

1050

1051

1052

1053

1054

1055

1056

1057

1058

Figure 5: Exploratory analysis of differences in deliberate recall as a function of age at the time of the prompted event. A: Model predictions for mean internal (left) and external (right) details recalled as a function of the time period of the prompts. Shaded distributions are posterior predictive distributions for mean details, and black points and error bars represent posterior medians and 95\% intervals. B: Posterior distributions representing differences in mean recall for each pair of time periods (adolescence > childhood, young adulthood > childhood, and young adulthood > adolescence). Shaded distributions represent all posterior contrast samples, and error bars represent $95 \%$ intervals.

Differences in prompted recall as a function of age at the time of the prompted event

To probe factors impacting prompted recall, we explored differences in recalled details as a function of the developmental time period of the prompted event (these exploratory analyses were not adjusted for multiple comparisons). Prior studies of autobiographical memory have found worse memory (e.g., fewer internal details) for memories from early childhood vs. other time periods (Bauer, 2007; Newcombe et al., 2000; Rubin \& Schulkind, 1997). This analysis therefore offered a post-hoc manipulation check that our memory scoring procedures were sensitive to these reported effects. 
Using the Bayesian multilevel linear regression model previously fit to test the music

1060

1061

1062

1063

1064

1065

1066

1067

1068

1069

1070

1071

1072

1073

1074

1075

1076

1077

1078

1079

1080

1081

1082

1083

1084

condition manipulation, we found that participants recalled more internal details on average for events in adolescence $(\beta=3.26,95 \% \mathrm{HDI}[2.41,4.11])$ and young adulthood $(\beta=4.61,95 \% \mathrm{HDI}$ $[3.63,5.56])$ compared to childhood (Fig. 5). Participants also recalled more internal details for events in young adulthood compared to adolescence ( $\beta=1.35,95 \%$ HDI $[0.57,2.12])$.

Participants recalled more external details for events in childhood compared to adolescence $(\beta=1.54,95 \% \mathrm{HDI}[0.57,2.39])$ and young adulthood $(\beta=1.41,95 \% \mathrm{HDI}[0.40,2.41])$, though there were no differences in external details between young adulthood and adolescence $(\beta=0.13,95 \% \mathrm{HDI}[-0.63,0.95])$. Recall of all details (internal + external) was greater for events in both adolescence $(\beta=1.72,95 \% \mathrm{HDI}[0.78,2.74])$ and young adulthood $(\beta=3.20,95 \% \mathrm{HDI}$ $[2.02,4.45])$ compared to childhood, and also greater for young adulthood compared to adolescence $(\beta=1.49,95 \% \mathrm{HDI}[0.31,2.67])$. In addition, the percentage of details recalled that were internal was greater for events in both adolescence $(\beta=8.81,95 \% \mathrm{HDI}[6.31,11.51])$ and young adulthood $(\beta=10.69,95 \%$ HDI $[8.00,13.45])$ compared to childhood, and also greater for young adulthood compared to adolescence $(\beta=1.88,95 \%$ HDI $[0.09,3.62])$. In general, effect sizes were larger for differences in internal details compared to external details, and for childhood compared to other developmental periods (e.g. smaller for comparisons between adolescence and young adulthood). These results therefore concord with prior work in showing worse autobiographical recall for events from early childhood (Newcombe et al., 2000; Pillemer \& White, 1989; Rubin \& Schulkind, 1997).

\section{Differences in prompted recall as a function of event prompts}

We explored whether different event prompts influenced recall of internal or external details. Visualization of the estimated proportion of internal details recalled for each prompt revealed substantial variability among prompts, even those within the same time window (Fig. 6). We also found substantial variability between prompts in the total number of details recalled 
1085 (see Supplemental Fig. 14). These large differences may have made it more difficult to find

1086 more subtle memory differences due to music condition, a topic we return to in the Discussion.

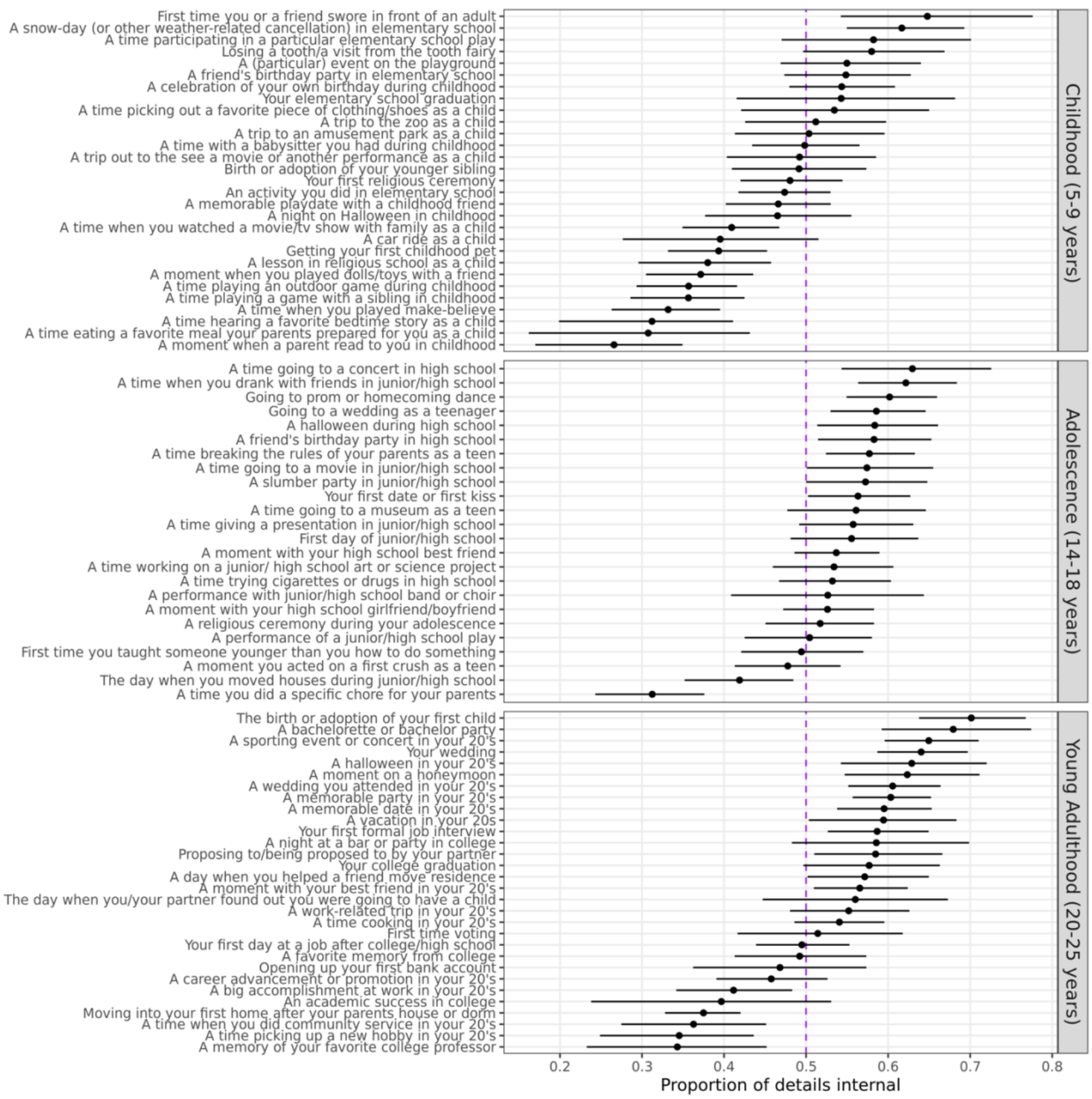

1090 Figure 6: Exploratory analysis of differences in deliberate recall as a function of prompt. X-axis 1091 shows the estimated average proportion of details that are internal for responses to each prompt. Points are posterior medians and error bars are $95 \%$ posterior intervals. The $y$-axis indicates each specific prompt grouped by each time period. Only prompts that $\geq 10$ participants responded to are included in this visualization. Prompts are sorted by highest to lowest proportion of internal details, separately for each time period. 


\section{Discussion}

1098

1099

1100

1101

1102

1103

1104

1105

1106

1107

1108

1109

1110

1111

1112

1113

1114

1115

1116

1117

1118

1119

1120

1121

1122

We examined whether hearing familiar music (vs. unfamiliar music or non-music audio) impacted autobiographical memory recall for prompted events in healthy adults ages 65-80 years. We created customized music lists for each participant to manipulate music familiarity, overcoming limitations of prior work that assumes which music may have been unfamiliar (Foster \& Valentine, 1998; Irish et al., 2006; Salakka et al., 2021). Our manipulation of participants' familiarity with the music clips was successful, yielding robust differences in familiarity between familiar and unfamiliar music conditions. Nevertheless, we observed no differences across music conditions in deliberate autobiographical memory recall in response to pre-selected event prompts. According to preregistered criteria, we found no effects of exposure to familiar music versus unfamiliar music, nor music versus non-music clips, on prompted episodic or non-episodic recall. Further, participant-reported familiarity with music clips was not associated with deliberate autobiographical recall. At the same time, the music exposure manipulation influenced both spontaneous recall and affect, such that hearing familiar music clips (compared to both unfamiliar music and non-music clips) evoked more spontaneous memories and more positive affect on average. Overall, our results provide evidence that, among healthy aging adults and within the context of the current paradigm, effects of hearing familiar music on autobiographical recall may be specific to memories directly triggered by the music, rather than extending to more deliberate recall of distinct memories.

\section{Specificity of music exposure effects on memory recall}

The current investigation did not find effects of music exposure on recall of pre-selected prompted events. Although prompted recall of all details (episodic and non-episodic) was numerically higher following hearing music compared to non-music clips, this effect did not meet preregistered criteria. However, our results were concordant with prior findings that familiar 
1123 music evokes spontaneous memories more often in comparison to unfamiliar music (Janata et

1124 al., 2007; Salakka et al., 2021). Thus, the absence of effects of music exposure on prompted

1125 autobiographical recall helps to distinguish which aspects of memory retrieval can be influenced 1126 by listening to music.

1127 Unlike most prior work, voluntarily recalled memories in the present study were nearly 1128 always distinct from any memories spontaneously evoked by the music (see Fig. 2D). Although

1129 recent work has investigated both involuntary and voluntary music-evoked autobiographical 1130 memories, in most studies participants were instructed to retrieve a memory in response to each 1131 music cue (Belfi et al., 2020, 2022; Sheldon et al., 2020; Sheldon \& Donahue, 2017) or describe 1132 memories that came to mind during music exposure (Baird et al., 2018; Belfi et al., 2016; El Haj, 1133 Fasotti, et al., 2012; Jakubowski \& Eerola, 2021). Therefore, even voluntary (as opposed to 1134 memory spontaneously evoked by music) retrieval in most prior studies consisted of responses 1135 directly to the music, rather than recall of separate memories. Because the current paradigm 1136 specifically examined recall for events distinct from those that came to mind during music 1137 exposure, our findings suggest that music effects on autobiographical recall may be limited to 1138 memories recalled specifically in response to music clips.

1139 The presence of effects of familiar music on spontaneous, but not prompted, recall in the 1140 current study suggests that while familiar music may serve as a cue for specific events or 1141 semantic information, it may not induce a 'retrieval mode' of broadly enhanced recall. Though 1142 multiple lines of evidence indicate that exposure to familiar stimuli can evoke a state of 1143 enhanced retrieval (Tarder-Stoll, Jayakumar, et al., 2020), such effects may last only seconds 1144 (Patil \& Duncan, 2018) which potentially explains why music familiarity did not impact prompted 1145 recall in the current study. More broadly, if encoding and retrieval modes only persist for several 1146 seconds after the offset of familiar stimuli (Meeter et al., 2004), free autobiographical recall 1147 paradigms allowing participants minutes to recall memories may not be well-suited to examine 1148 such states. 
We emphasize that the absence of effects of music on deliberate recall does not

1150 contradict prior work showing that exposure to familiar music can facilitate retrieval of

1151 information encoded during (or very close in time to) prior listening through associative, or

1152 context-dependent, mechanisms (Balch et al., 1992; Janata, 2009; Kubit \& Janata, 2022). In the

1153 current study prior music exposure was not precisely synchronized in time (within a 5-year

1154 window at best) with the prompted events; thus, the music clips were likely only weakly

1155 associated with most prompted memories. In particular, participants reported lower exposure to

1156 music released during childhood within the time window of its release (see Supplemental Fig.

1157 13), yet high familiarity for this music overall (see Supplemental Fig. 15A); this suggests that

1158 familiarity may have come from listening at later times. It is therefore unlikely that the music

1159 clips had strong associative links to the prompted events, unlike the links that may exist in prior

1160 studies that play music concurrently or in close proximity to to-be-remembered information.

\section{Potential methodological explanations for the absence of music effects on deliberate recall}

1164 prompted autobiographical recall. Here, we consider several reasons-beyond a true null

1165 effect-that may have contributed to this lack of a difference. First, one concern may be that

1166 high within-participant variance for deliberate recall measures (internal and external details),

1167 even within music conditions and time periods, may have lowered the statistical power of the

1168 current study to identify music exposure effects (Baker et al., 2021). Such variance in recall was

1169 likely due to the fact that prompted events varied in autobiographical salience (see Fig. 6).

1170 However, observed within-participant variance was roughly consistent with that used to perform

1171 sample size calculations, indicating that the current study was powered appropriately to detect

1172 true effects of approximately 2 details or larger (see Supplemental Fig. 12). 
1173 In the current study, participants heard music immediately before memory prompts were

1174 given, but not during recall. Although prompted recall began only seconds after the end of each

1175 music clip, it is possible that the temporal separation of the music listening and recall processes

1176 may have diminished true music effects that would have been observed had the music been

1177 played during recall. Indeed, some studies of music-evoked memory in patients with Alzheimer's

1178 or other forms of dementia have found effects of playing music clips softly in the background

1179 during memory retrieval (El Haj et al., 2015; Foster \& Valentine, 1998; Irish et al., 2006). Yet,

1180 several studies have found that music can enhance autobiographical memory retrieval for

1181 patients with Alzheimer's disease for at least several minutes after listening (El Haj et al., 2012;

1182 García et al., 2012). It is possible that the duration of effects differs for direct memory cues (i.e.,

1183 spontaneous memory recall) versus retrieval mode induction (i.e., for deliberate memory recall).

1184 Future work will be needed to test this possibility. In the present study, the use of Zoom

1185 videoconferencing prevented playing music during recall as it is difficult to listen to audio and

1186 speak at the same time using this platform. Subsequent studies could explore whether

1187 simultaneous versus preceding music presentation impacts prompted or spontaneous memory

1188 retrieval.

1189 In addition, unlike some previous work, the familiar music stimuli were chosen by the 1190 experimenters (not directly by the participants), and unfamiliar music stimuli were matched in 1191 sound quality. We consider both design choices to be strengths of the study for mitigating 1192 potential confounds (i.e., differences in sonic features, or if participants were able to choose the 1193 familiar, but not unfamiliar music clips). However, it is possible that some mnemonic effects of 1194 familiar music observed in the literature are driven by participants' preference for their chosen 1195 music, or because unfamiliar music clips were a different (or entirely unfamiliar) genre of music. 1196 Here, because unfamiliar music clips were selected by the research team to be stylistically 
1197 similar to the familiar music clips, any potential effects of familiarity with the music genre (as

1198 opposed to familiarity with specific songs) would not have been observed.

1199

1200

1201

1202

1203

1204

1205

1206

1207

1208

1209

1210

1211

1212

1213

1214

1215

1216

1217 Talamini et al., 2022). Additionally, it is possible that participants' music-evoked emotions in the

\section{Music-evoked affect was not sufficient to impact deliberate autobiographical recall}

Consistent with prior work indicating that more familiar music evokes more positive emotions (Belfi et al., 2022; Gabard-Durnam et al., 2018; Kathios et al., 2022; Salakka et al., 2021) and that music generally induces pleasure and reward processes in most people (Belfi et al., 2021; Belfi \& Loui, 2020; Peretz, 2006), our music manipulation induced changes in affect. Participants reported feeling most positive after listening to familiar music compared to unfamiliar music or non-music clips, and more positive after listening to unfamiliar music compared to non-music clips (Supplemental Fig. 9A).

However, music-evoked affect was not associated with recall of prompted memories (Supplemental Fig. 9B-C). While previous work has found that pleasure evoked by music can boost associative memory for non-musical information encoded during listening (in particular, through dopaminergic modulation of memory consolidation; see Ferreri \& Rodriguez-Fornells, 2022), the present results indicate that such mood induction may not be sufficient to impact deliberate autobiographical recall. Alternatively, because hearing music may most strongly influence emotionally congruent memories (i.e., positively valenced music impacts positively valenced memories), it is possible that mismatch between music-evoked emotions and the emotional content of prompted memories diminished such effects (Sheldon et al., 2020;

1218 current study were influenced by their expectations for the study paradigm. Although 1219 participants were informed that some audio clips played in the study would not be music, some 1220 expressed surprise and disappointment not to be hearing music while listening to the non-music

1221 clips. The lower affect ratings in the non-music condition then may have been due to violated 1222 expectations rather than more negative emotions evoked by the content of the clips. 
1223

1224

1225

1226

1227

1228

1229

1230

1231

1232

1233

1234

1235

1236

1237

1238

1239

1240

1241

1242

1243

1244

1245

1246

1247

Age-related and prompt-specific effects on deliberate autobiographical recall

After observing that music exposure did not impact deliberate autobiographical recall, we sought to explore whether other factors impacted retrieval of internal or external details.

Exploratory analyses indicated that participants retrieved more episodic information and less non-episodic information for prompted events that occurred in young adulthood (20-25 years) relative to adolescence (14-18 years) or childhood (5-9 years), and for adolescence relative to childhood. In particular, memories in the childhood time window contained the least episodic detail related to the prompted events, consistent with age-related increases in episodic memory from middle childhood through adolescence (Bauer \& Larkina, 2014; Ghetti \& Angelini, 2008; Ghetti \& Bunge, 2012; Nelson, 2018; Usher \& Neisser, 1993; Willoughby et al., 2012).This finding further aligns with previous findings of 'reminiscence bumps' of enhanced memory among older adults for events in adolescence and young adulthood, compared to other time periods (Jakubowski et al., 2020; Krumhansl \& Zupnick, 2013; Schlagman et al., 2007). In addition, participants recalled the most non-episodic information (or information for nonprompted episodes) in response to prompts from childhood, indicating potential compensatory mechanisms for the lack of episodic retrieval (Lalla et al., 2022). While differences in recall among developmental time periods cannot be fully distinguished from impacts of recency (Moreton \& Ward, 2010), that all prompted events were remote ( $\geq 40$ years before the study) may have reduced the magnitude of potential recency effects.

Even within each time window, recall of episodic information varied substantially as a function of the specific event prompted (see Fig. 6). Event prompts were randomly assigned to a music condition for each participant to avoid prompt-induced confounds. However, as previously discussed, high within-participant variance in deliberate recall due to prompt effects may have made it more difficult to detect recall differences due to music exposure. In future investigations, 
1248 researchers may consider selecting prompts that are relatively well-matched in average evoked

1249 memory content (Fig. 6) to minimize unwanted sources of variability in recall.

Non-music clips evoked spontaneous memories more often than unfamiliar music

Familiar music clips evoked spontaneous memories most often, but we also found that

1253 non-music clips evoked spontaneous memories more often than unfamiliar music (see Fig. 2C).

1254 In line with these findings, some prior work has found that unfamiliar music elicits fewer

1255 autobiographical memories compared to environmental sounds or word cues, suggesting that

1256 unfamiliar music may not be a strong retrieval cue for many memories (Jakubowski \& Eerola,

1257 2021). Unfamiliar clips may shift focus away from retrieval and towards an "encoding mode" in

1258 which participants attend to sonic features, lyrics, or musical event structures (Janata, 2005;

1259 Janata et al., 2002; Williams et al., 2022). Further, participants in the current study may have

1260 focused their attention on trying to identify the unfamiliar music clips; this could have

1261 suppressed memory retrieval. Alternatively, the non-music clips played in the current study may

1262 have cued comparatively more specific associations based on their semantic content (news, 1263 weather, traffic).

1264 It is noteworthy that this difference between unfamiliar music and non-music clips was

1265 specific to spontaneous memory recall and did not extend to deliberate recall. Thus, the

1266 cognitive variables that may have suppressed spontaneous memories in response to unfamiliar

1267 music did not similarly affect the ability to deliberately search for a distinct memory.

1268

1269

\section{Limitations and Future Directions}

1270 Several limitations to the current study may be addressed with further research. First,

1271 while the Autobiographical Interview allowed us to measure what types of details were recalled,

1272 the internal versus external designations of details represent extremely broad categorizations.

1273 Future work could also take a more fine-grained approach to understand whether recall of 
1274 subcategories of details (for example, perceptual, emotion/thought, place, or time details) are

1275 impacted by music exposure. Furthermore, the current study only investigated remote

1276 autobiographical recall; future investigations could explore whether music exposure impacts

1277 recall of more recent events. Further studies may also benefit from using additional

1278 measurements of autobiographical recall that allow for verifying the accuracy of participants'

1279 memories (Barclay \& Wellman, 1986; Cabeza \& St Jacques, 2007) or rely less on manual

1280 experimenter scoring of recalled details (for example via automated software, see Genugten \&

1281 Schacter, 2022).

Our measurements of spontaneous memory were also limited to binary responses

1283 indicating the presence versus absence of a memory evoked by each clip. We did not ask

1284 participants to elaborate or share further details on spontaneously evoked memories in efforts to

1285 avoid burdening participants with longer study sessions and because the main hypotheses of

1286 the study concerned prompted memory. Because we only measured the presence or absence

1287 of evoked memories, our work does not speak to the quality of music-evoked autobiographical

1288 memories (i.e. MEAMs; see Belfi et al., 2020; Janata et al., 2007). Although there is much

1289 reason, based on prior literature, to expect reports of detailed autobiographical memories in

1290 response to music, there is also the possibility that such memories may be relatively weak or

1291 gist-like. In particular, familiar stimuli associated with many events are weaker associative cues

1292 for episodic recall compared to stimuli only associated with one specific event (i.e. 'fan effects';

1293 Badham et al., 2016; Tulving \& Thomson, 1973). In the current study, if the familiar music clips

1294 were broadly associated with many events, it is possible that the spontaneous memories these

1295 clips elicited were gist-like, rather than strongly episodic. Broad associative links of familiar

1296 music may have also interfered with the ability to deliberately access other memories not

1297 directly associated with the music; however, such an explanation may lead to the prediction of

1298 worse deliberate recall following familiar versus unfamiliar music, which we did not observe. 
1299 Nevertheless, discussion of such fan effects is purely speculative based on the current 1300 paradigm; future research aiming to investigate relationships between spontaneous and 1301 prompted retrieval would benefit from allowing participants to freely recall both types of 1302 memories.

The current study was conducted via Zoom videocalls so as not to increase participants' 1304 risk of COVID-19 infection. This format may have had unintended effects on both the 1305 experience of music listening and memory recall. Although participants were instructed to 1306 choose a consistent and comfortable volume for music listening at the beginning of each 1307 session, we were not able to ensure that the quality and volume of audio were constant across 1308 sessions. In addition, it is possible that participants felt less energetic (i.e., through "Zoom 1309 fatigue" mechanisms) or less comfortable sharing memories with an experimenter over Zoom 1310 than they would have been in person. Although the video call format allowed this study to be 1311 conducted given the circumstances, impacts of music on memory may be explored with more 1312 experimental control within in-person lab environments. An additional limitation of the study design is that experimenters were aware of the goals

1314 of the study and music condition during each session. Therefore, it is possible that

1315 experimenters may have unintentionally altered their interactions with participants based on 1316 knowledge of the study condition (Schulz \& Grimes, 2002). While we do not believe such biases 1317 likely gave rise to the current results (given the absence of hypothesized effects on deliberate 1318 recall), further work could eliminate such potential biases by computerizing experimental 1319 procedures or otherwise ensuring that experimenters are unaware of the condition while 1320 interacting with participants. Relatedly, while participants did not know the goals, hypothesis, or 1321 manipulations of the study, the fact that different sound clips were played in each session was 1322 necessarily transparent to them. Thus, participants may have been able to guess aspects of the 1323 study design, which could have introduced demand characteristics (Gillihan et al., 2007). For 
1324 example, participants may have thought experimenters expected them to recall more in the

1325 music conditions compared to the non-music clips.

1326 We also note several limitations to the generalizability of the current findings. The

1327 studied cohort was a highly educated majority-White sample recruited mostly from the United

1328 States. Moreover, that participants self-selected for a study involving Zoom videoconferencing

1329 and listening to popular music likely yielded a non-representative sample among healthy adults

1330 ages 65-80 years. Further, the study inclusion criteria selected for a cohort that probably was

1331 more familiar with popular music and higher in memory function compared to other adults in the

1332 same age range. Finally, the music stimuli themselves only represented a small subset of

1333 styles, and the vast majority of lyrics were in English. It is possible that impacts of music on

1334 autobiographical memory differ for different populations (for example, participants of different

1335 ages or cultural backgrounds) or styles of music.

1336 In particular, individuals with dementia or other memory disorders may experience effects of

1337 music on autobiographical memory not observed among the healthy participants in the current

1338 study. Several prior studies have found evidence for effects of music on autobiographical

1339 memory in Alzheimer's patients but not healthy control individuals (El Haj et al., 2013, 2015;

1340 Irish et al., 2006). Thus, different processes may underlie music-induced effects on memory in

1341 memory-impaired patients compared to healthy individuals. Future work examining impacts of

1342 music exposure on memory for both healthy participants and patients with memory disorders -

1343 while avoiding ceiling effects in healthy participants-will be important in understanding whether

1344 common mechanisms exist.

1345 Crucially, lack of music-evoked effects on recall of distinct prompted memories does not

1346 preclude the usefulness of music-based therapies (Taylor, 1997). That music can provoke

1347 spontaneous recall and induce positive affect is sufficient motivation for further development of

1348 music-based techniques in a variety of treatment settings. Indeed, music-based therapies may

1349 be powerful even if effects are somewhat general and not limited to memory. For example, for 
1350 patients with Alzheimer's disease, music therapies have been shown to act through non-

1351 mnemonic mechanisms (e.g., arousal, affect, self-consciousness, linguistic function; see Peck

1352 et al., 2016 for review). Recent work has also highlighted potential music-based interventions

1353 targeting auditory and reward systems for healthy aging adults (Quinci et al., 2022).

1354

1355 Conclusions

1356

The results of the current study indicate that among healthy adults ages $65-80$ years,

1357 exposure to familiar music (vs. unfamiliar music or non-music audio), evoked spontaneous

1358 memories more often. Familiar music did not, however, impact voluntary recall of distinct

1359 prompted events. If translated to clinical populations, these findings may be able to help

1360 optimize methods and target outcomes for music-based therapies (Loui, 2020; Thaut \&

1361 Hoemberg, 2014). As there is much need to develop and refine non-pharmacological treatments

1362 for dementia and other memory disorders (Baird et al., 2019), it will be important for further

1363 research to explore how music can influence memory, and what types of memories are

1364 impacted.

1365

1366

1367 
Deidentified data are available at https://osf.io/56khe/.

Paul Alexander Bloom: Conceptualization, Methodology, Investigation, Visualization,

1373 Software, Data Curation, Project administration, Formal analysis, Writing - Original Draft, Writing

1374 - Review \& Editing, Ella Bartlett: Methodology, Investigation, Data Curation, Writing - Review

1375 \& Editing Nicholas Kathios: Methodology, Investigation, Data Curation, Formal analysis, Visualization, Writing - Review \& Editing Sameah Algharazi: Methodology, Investigation, Data Curation, Formal analysis, Writing - Review \& Editing Matthew Siegelman: Software Fan Shen: Software, Formal analysis Lea Beresford: Investigation, Formal analysis, Writing Review \& Editing Michaelle Evangeline DiMaggio-Potter: Investigation, Software, Formal analysis, Writing - Review \& Editing Anshita Singh: Project administration, Formal analysis, Writing - Review \& Editing Sarah Bennett: Investigation, Formal analysis, Writing - Review \& Editing Nandhini Natarajan: Investigation, Formal analysis, Writing - Review \& Editing Hannah Lee: Formal analysis, Writing - Review \& Editing Sumra Sajid: Formal analysis, Writing Review \& Editing Erin Joyce: Investigation, Formal analysis, Writing - Review \& Editing Rachel Flora Fischman: Investigation, Formal analysis, Writing - Review \& Editing Samuel Hutchinson: Investigation, Formal analysis, Writing - Review \& Editing Sophie Pan: Investigation, Formal analysis, Writing - Review \& Editing Nim Tottenham: Supervision, Conceptualization, Methodology, Resources, Writing - Review \& Editing Mariam Aly: Supervision, Conceptualization, Methodology, Resources, Writing - Original Draft, Writing Review \& Editing

\section{Acknowledgments}

We thank the participants for contributing their time and energy to this study. We also

1395 thank Amaesha Durazi, Nicolas Camacho, Monica Thieu, Carina Fan, R.B., and the DANLAB

1396 and Alyssano groups for their contributions and feedback.

1397

\section{Funding}

This work was supported by a National Science Foundation Graduate Fellowship to PAB (DGE 1644869) and a National Science Foundation CAREER Award to MA (BCS-1844241).

\section{Conflicts of Interest}

We have no known conflicts of interest to disclose. 
1407 Aalbers, S., Fusar-Poli, L., Freeman, R. E., Spreen, M., Ket, J. C., Vink, A. C., Maratos, A., 1408 Crawford, M., Chen, X.-J., \& Gold, C. (2017). Music therapy for depression. Cochrane 1409 Database of Systematic Reviews, 11. https://doi.org/10.1002/14651858.CD004517.pub3

1410 Acevedo-Molina, M. C., Matijevic, S., \& Grilli, M. D. (2020). Beyond episodic remembering: Elaborative retrieval of lifetime periods in young and older adults. Memory, 28(1), 8393. https://doi.org/10.1080/09658211.2019.1686152

1413 Alonso, I., Davachi, L., Valabrègue, R., Lambrecq, V., Dupont, S., \& Samson, S. (2016). Neural correlates of binding lyrics and melodies for the encoding of new songs. Neurolmage, 127, 333-345. https://doi.org/10.1016/j.neuroimage.2015.12.018

Arroyo-Anlló, E. M., Díaz, J. P., \& Gil, R. (2013). Familiar Music as an Enhancer of SelfConsciousness in Patients with Alzheimer's Disease. BioMed Research International, 2013. https://doi.org/10.1155/2013/752965

1419 Badham, S. P., Poirier, M., Gandhi, N., Hadjivassiliou, A., \& Maylor, E. A. (2016). Aging and memory as discrimination: Influences of encoding specificity, cue overload, and prior knowledge. Psychology and Aging, 31(7), 758-770. https://doi.org/10.1037/pag0000126

1422 Baird, A., Brancatisano, O., Gelding, R., \& Thompson, W. F. (2018). Characterization of Music 1423 and Photograph Evoked Autobiographical Memories in People with Alzheimer's Disease. Journal of Alzheimer's Disease, 66(2), 693-706. https://doi.org/10.3233/JAD-180627 
1425 Baird, A., Brancatisano, O., Gelding, R., \& Thompson, W. F. (2020). Music evoked

1426

1427

1428

1429

1430

1431

1432

1433

1434

1435

1436

1437

1438

1439

1440

1441

1442

1443

1444

1445

autobiographical memories in people with behavioural variant frontotemporal

dementia. Memory, 28(3), 323-336. https://doi.org/10.1080/09658211.2020.1713379

Baird, A., Garrido, S., \& Tamplin, J. (2019). Music and Dementia: From Cognition to Therapy. Oxford University Press.

Baird, A., Gelding, R., Brancatisano, O., \& Thompson, W. F. (2020). A Preliminary Exploration of the Stability of Music- and Photo-Evoked Autobiographical Memories in People with Alzheimer's and Behavioral Variant Frontotemporal Dementia. Music \& Science, 3, 2059204320957273. https://doi.org/10.1177/2059204320957273

Baird, A., \& Samson, S. (2009). Memory for Music in Alzheimer's Disease: Unforgettable? Neuropsychology Review, 19(1), 85-101. https://doi.org/10.1007/s11065-009-9085-2

Baird, A., \& Samson, S. (2014). Music evoked autobiographical memory after severe acquired brain injury: Preliminary findings from a case series. Neuropsychological Rehabilitation, 24(1), 125-143. https://doi.org/10.1080/09602011.2013.858642

Baird, A., \& Samson, S. (2015). Chapter 11-Music and dementia. In E. Altenmüller, S. Finger, \& F. Boller (Eds.), Progress in Brain Research (Vol. 217, pp. 207-235). Elsevier. https://doi.org/10.1016/bs.pbr.2014.11.028

Baker, D. H., Vilidaite, G., Lygo, F. A., Smith, A. K., Flack, T. R., Gouws, A. D., \& Andrews, T. J. (2021). Power contours: Optimising sample size and precision in experimental psychology and human neuroscience. Psychological Methods, 26(3), 295-314. https://doi.org/10.1037/met0000337 
1446 Baker, F. (2001). Rationale for the Effects of Familiar Music on Agitation and Orientation Levels

1447 of People in Posttraumatic Amnesia. Nordic Journal of Music Therapy, 10(1), 32-41.

$1448 \quad$ https://doi.org/10.1080/08098130109478015

1449 Baker, F. (2009). Post traumatic amnesia and music: Managing behavior through song. VDM

1450 Verlag Dr. Müller. http://espace.library.uq.edu.au/view/UQ:189580

1451 Balch, W. R., Bowman, K., \& Mohler, L. A. (1992). Music-dependent memory in immediate and

1452 delayed word recall. Memory \& Cognition, 20(1), 21-28.

$1453 \quad$ https://doi.org/10.3758/BF03208250

1454 Balteş, F. R., Avram, J., Miclea, M., \& Miu, A. C. (2011). Emotions induced by operatic music:

1455 Psychophysiological effects of music, plot, and acting: A scientist's tribute to Maria

$1456 \quad$ Callas. Brain and Cognition, 76(1), 146-157.

1457 https://doi.org/10.1016/j.bandc.2011.01.012

1458 Barclay, C. R., \& Wellman, H. M. (1986). Accuracies and inaccuracies in autobiographical

1459 memories. Journal of Memory and Language, 25(1), 93-103.

1460

https://doi.org/10.1016/0749-596X(86)90023-9

1461 Bartlett, J. C., \& Snelus, P. (1980). Lifespan Memory for Popular Songs. The American Journal of Psychology, 93(3), 551-560. https://doi.org/10.2307/1422730

1463 Basaglia-Pappas, S., Laterza, M., Borg, C., Richard-Mornas, A., Favre, E., \& Thomas-Antérion, C. 1464 (2013). Exploration of verbal and non-verbal semantic knowledge and autobiographical 1465 memories starting from popular songs in Alzheimer's disease. International 1466 Psychogeriatrics, 25(5), 785-795. https://doi.org/10.1017/S1041610212002359 
1467 Bauer, P. J. (2007). Recall in Infancy: A Neurodevelopmental Account. Current Directions in

1468

1469

1470

1471

1472

1473

1474

1475

1476

1477

1478

1479

1480

1481

1482

1483

1484

1485

1486

1487

Psychological Science, 16(3), 142-146. https://doi.org/10.1111/j.1467-

8721.2007.00492.x

Bauer, P. J. (2012). The life I once remembered: The waxing and waning of early memories. In D.

C. Rubin \& D. Berntsen (Eds.), Understanding Autobiographical Memory: Theories and Approaches (pp. 205-225). Cambridge University Press.

https://doi.org/10.1017/CBO9781139021937.016

Bauer, P. J., \& Larkina, M. (2014). Childhood amnesia in the making: Different distributions of autobiographical memories in children and adults. Journal of Experimental Psychology. General, 143(2), 597-611. https://doi.org/10.1037/a0033307

Baur, B., Uttner, I., Ilmberger, J., Fesl, G., \& Mai, N. (2000). Music memory provides access to verbal knowledge in a patient with global amnesia. Neurocase, 6(5), 415-421. https://doi.org/10.1080/13554790008402712

Belfi, A. M., Bai, E., \& Stroud, A. (2020). Comparing Methods for Analyzing Music-Evoked Autobiographical Memories. Music Perception, 37(5), 392-402. https://doi.org/10.1525/mp.2020.37.5.392

Belfi, A. M., Bai, E., Stroud, A., Twohy, R., \& Beadle, J. N. (2022). Investigating the role of involuntary retrieval in music-evoked autobiographical memories. Consciousness and Cognition, 100, 103305. https://doi.org/10.1016/j.concog.2022.103305

Belfi, A. M., Karlan, B., \& Tranel, D. (2016). Music evokes vivid autobiographical memories. Memory, 24(7), 979-989. https://doi.org/10.1080/09658211.2015.1061012 
1488 Belfi, A. M., \& Loui, P. (2020). Musical anhedonia and rewards of music listening: Current advances and a proposed model. Annals of the New York Academy of Sciences, 1464(1), 99-114. https://doi.org/10.1111/nyas.14241

Belfi, A. M., Moreno, G. L., Gugliano, M., \& Neill, C. (2021). Musical reward across the lifespan. Aging \& Mental Health, O(0), 1-8. https://doi.org/10.1080/13607863.2021.1871881

Blackburn, R., \& Bradshaw, T. (2014). Music therapy for service users with dementia: A critical

Blais-Rochette, C., \& Miranda, D. (2016). Music-evoked autobiographical memories, emotion regulation, time perspective, and mental health. Musicae Scientiae, 20(1), 26-52.

Bower, J., \& Shoemark, H. (2012). Music Therapy for the Pediatric Patient Experiencing https://doi.org/10.1177/1029864915626967

Brotons, M., Koger, S. M., \& Pickett-Cooper, P. (1997). Music and Dementias: A Review of 1506

Brotons, M., \& Koger, S. M. (2000). The Impact of Music Therapy on Language Functioning in Dementia. Journal of Music Therapy, 37(3), 183-195. https://doi.org/10.1093/jmt/37.3.183 Literature. Journal of Music Therapy, 34(4), 204-245. https://doi.org/10.1093/jmt/34.4.204

Bürkner, P.-C. (2019). brms: Bayesian Regression Models using "Stan" (2.10.0). https://CRAN.Rproject.org $/$ package=brms 
1510 Bürkner, P.-C., \& Vuorre, M. (2019). Ordinal Regression Models in Psychology: A Tutorial.

1511

1512

1513

1514

1515

1516

1517

1518

1519

1520

1521

1522

1523

1524

1525

1526

1527

1528

1529

1530

Advances in Methods and Practices in Psychological Science, 2(1), 77-101.

https://doi.org/10.1177/2515245918823199

Cabeza, R., \& St Jacques, P. (2007). Functional neuroimaging of autobiographical memory.

Trends in Cognitive Sciences, 11(5), 219-227. https://doi.org/10.1016/j.tics.2007.02.005

Cady, E. T., Harris, R. J., \& Knappenberger, J. B. (2008). Using music to cue autobiographical memories of different lifetime periods. Psychology of Music, 36(2), 157-177. https://doi.org/10.1177/0305735607085010

census.gov. (2019). U.S. Census Bureau QuickFacts: United States.

https://www.census.gov/quickfacts/fact/table/US/PST045219

Chung, Y., Gelman, A., Rabe-Hesketh, S., Liu, J., \& Dorie, V. (2015). Weakly Informative Prior for Point Estimation of Covariance Matrices in Hierarchical Models. Journal of Educational and Behavioral Statistics, 40(2), 136-157. https://doi.org/10.3102/1076998615570945

Cross, K., Flores, R., Butterfield, J., Blackman, M., \& Lee, S. (2012). The Effect of Passive Listening versus Active Observation of Music and Dance Performances on Memory Recognition and Mild to Moderate Depression in Cognitively Impaired Older Adults. Psychological Reports, 111(2), 413-423.

https://doi.org/10.2466/10.02.13.PR0.111.5.413-423

Decker, A. L., \& Duncan, K. (2020). Acetylcholine and the complex interdependence of memory and attention. Current Opinion in Behavioral Sciences, 32, 21-28.

https://doi.org/10.1016/j.cobeha.2020.01.013 
1531 Duncan, K. D., \& Shohamy, D. (2016). Memory states influence value-based decisions. Journal of 1532 Experimental Psychology. General, 145(11), 1420-1426.

1533 https://doi.org/10.1037/xge0000231

1534 Duncan, K., Semmler, A., \& Shohamy, D. (2019). Modulating the Use of Multiple Memory 1535 Systems in Value-based Decisions with Contextual Novelty. Journal of Cognitive 1536 Neuroscience, 31(10), 1455-1467. https://doi.org/10.1162/jocn_a_01447

1537 El Haj, M., Antoine, P., Nandrino, J. L., Gély-Nargeot, M.-C., \& Raffard, S. (2015). Self-defining 1538 1539 memories during exposure to music in Alzheimer's disease. International Psychogeriatrics, 27(10), 1719-1730. https://doi.org/10.1017/S1041610215000812

1540 El Haj, M., Clément, S., Fasotti, L., \& Allain, P. (2013). Effects of music on autobiographical 1541 1542 verbal narration in Alzheimer's disease. Journal of Neurolinguistics, 26(6), 691-700. https://doi.org/10.1016/j.jneuroling.2013.06.001

1543 El Haj, M., Fasotti, L., \& Allain, P. (2012). The involuntary nature of music-evoked autobiographical memories in Alzheimer's disease. Consciousness and Cognition, 21(1), 238-246. https://doi.org/10.1016/j.concog.2011.12.005

1546 El Haj, M., Postal, V., \& Allain, P. (2012). Music Enhances Autobiographical Memory in Mild Alzheimer's Disease. Educational Gerontology, 38(1), 30-41. https://doi.org/10.1080/03601277.2010.515897

1549 Fan, C., Romero, K., \& Levine, B. (2019). Older adults with lower autobiographical memory $1550 \quad$ abilities report less age-related decline in everyday cognitive function. 1551 https://doi.org/10.31234/osf.io/zqs78 
1552 Fang, R., Ye, S., Huangfu, J., \& Calimag, D. P. (2017). Music therapy is a potential intervention 1553 for cognition of Alzheimers Disease: A mini-review. Translational Neurodegeneration; London, 6. http://dx.doi.org.ezproxy.cul.columbia.edu/10.1186/s40035-017-0073-9

1555

Ferreri, L., Bigand, E., Perrey, S., Muthalib, M., Bard, P., \& Bugaiska, A. (2014). Less Effort, Better Results: How Does Music Act on Prefrontal Cortex in Older Adults during Verbal Encoding? An fNIRS Study. Frontiers in Human Neuroscience, 8. https://doi.org/10.3389/fnhum.2014.00301

Ferreri, L., \& Rodriguez-Fornells, A. (2022). Memory modulations through musical pleasure. Annals of the New York Academy of Sciences, $n / a(n / a)$. https://doi.org/10.1111/nyas.14867

Folstein, M., Folstein, S., \& McHugh, P. (1975). “Mini-mental state”. A practical method for grading the cognitive state of patients for the clinician. Journal of Psychiatric Research, 12(3), 189-198. https://doi.org/10.1016/0022-3956(75)90026-6

Ford, J. H., Addis, D. R., \& Giovanello, K. S. (2011). Differential neural activity during search of specific and general autobiographical memories elicited by musical cues. Neuropsychologia, 49(9), 2514-2526. https://doi.org/10.1016/j.neuropsychologia.2011.04.032

Foster, N. A., \& Valentine, E. R. (1998). The Effect of Concurrent Music on Autobiographical Recall in Dementia Clients. Musicae Scientiae, 2(2), 143-155. https://doi.org/10.1177/102986499800200203 
1572 Foster, N. A., \& Valentine, E. R. (2001). The Effect of Auditory Stimulation on Autobiographical

1573 Recall in Dementia. Experimental Aging Research, 27(3), 215-228.

1574 https://doi.org/10.1080/036107301300208664

1575 Gabard-Durnam, L. J., Hensch, T. K., \& Tottenham, N. (2018). Music Reveals Medial Prefrontal Cortex Sensitive Period in Childhood. BioRxiv, 412007. https://doi.org/10.1101/412007

1577 García, J. J. M., Iodice, R., Carro, J., Sánchez, J. A., Palmero, F., \& Mateos, A. M. (2012).

$1578 \quad$ Improvement of autobiographic memory recovery by means of sad music in Alzheimer's

1579 Disease type dementia. Aging Clinical and Experimental Research, 24(3), 227-232.

$1580 \quad$ https://doi.org/10.3275/7874

1581 Gelman, A., Carlin, J. B., Stern, H. S., Dunson, D. B., Vehtari, A., \& Rubin, D. B. (2013). Bayesian Data Analysis, Third Edition. CRC Press.

1583 Genugten, R. van, \& Schacter, D. L. (2022). Automated Scoring of the Autobiographical $1584 \quad$ Interview with Natural Language Processing. PsyArXiv. https://doi.org/10.31234/osf.io/nyurm

1586 Gerdner, L. A. (2000). Effects of Individualized Versus Classical "Relaxation" Music on the 1587 Frequency of Agitation in Elderly Persons With Alzheimer's Disease and Related Disorders. International Psychogeriatrics, 12(01), 49-65. https://doi.org/10.1017/S1041610200006190

1590 Gerdner, L. A. (2012). Individualized music for dementia: Evolution and application of evidence1591 based protocol. World Journal of Psychiatry, 2(2), 26-32.

1592 https://doi.org/10.5498/wjp.v2.i2.26 
1593 Gerdner, L. A., Hartsock, J., \& Buckwalter, K. C. (2000). Assessment of Personal Music Preference 1594 (Family Version). The University of lowa Gerontological Nursing Interventions Research 1595 Center: Research Development and Dissemination Core. https://www.health.ny.gov/diseases/conditions/dementia/edge/forms/edge_project_in div_music_assessment.pdf

1598 Ghetti, S., \& Angelini, L. (2008). The development of recollection and familiarity in childhood and adolescence: Evidence from the dual-process signal detection model. Child Development, 79(2), 339-358. https://doi.org/10.1111/j.1467-8624.2007.01129.x

1601 Ghetti, S., \& Bunge, S. A. (2012). Neural changes underlying the development of episodic 1602 memory during middle childhood. Developmental Cognitive Neuroscience, 2(4), 381395. https://doi.org/10.1016/j.dcn.2012.05.002

1604 Gillihan, S. J., Kessler, J., \& Farah, M. J. (2007). Memories affect mood: Evidence from covert 1605 experimental assignment to positive, neutral, and negative memory recall. Acta Psychologica, 125(2), 144-154. https://doi.org/10.1016/j.actpsy.2006.07.009

Halpern, A., \& O’Connor, M. (2000). Implicit memory for music in Alzheimer's disease. Neuropsychology, 14(3), 391-397.

1609 Hanser, S. B., \& Thompson, L. W. (1994). Effects of a Music Therapy Strategy on Depressed Older Adults. Journal of Gerontology, 49(6), P265-P269.

1612 Hasselmo, M., \& Schnell, E. (1994). Laminar selectivity of the cholinergic suppression of synaptic transmission in rat hippocampal region CA1: Computational modeling and brain slice 
1614

1615

1616

1617

1618

1619

1620

1621

1622

1623

1624

1625

1626

1627

1628

1629

1630

1631

1632

1633

1634

physiology. Journal of Neuroscience, 14(6), 3898-3914.

https://doi.org/10.1523/JNEUROSCI.14-06-03898.1994

Hays, T., Bright, R., \& Minichiello, V. (2002). The Contribution of Music to Positive Aging: A Review. Journal of Aging and Identity, 7(3), 165-175.

https://doi.org/10.1023/A:1019712522302

Hobeika, L., \& Samson, S. (2020). Chapter 13-Why do music-based interventions benefit persons with neurodegenerative disease? In L. L. Cuddy, S. Belleville, \& A. Moussard (Eds.), Music and the Aging Brain (pp. 333-349). Academic Press.

https://doi.org/10.1016/B978-0-12-817422-7.00013-4

Holm, S. (1979). A Simple Sequentially Rejective Multiple Test Procedure. Scandinavian Journal of Statistics, 6(2), 65-70. JSTOR.

Irish, M., Cunningham, C. J., Walsh, J. B., Coakley, D., Lawlor, B. A., Robertson, I. H., \& Coen, R. F. (2006). Investigating the Enhancing Effect of Music on Autobiographical Memory in Mild Alzheimer's Disease. Dementia and Geriatric Cognitive Disorders, 22(1), 108-120. https://doi.org/10.1159/000093487

Jakubowski, K., Bashir, Z., Farrugia, N., \& Stewart, L. (2018). Involuntary and voluntary recall of musical memories: A comparison of temporal accuracy and emotional responses. Memory \& Cognition, 46(5), 741-756. https://doi.org/10.3758/s13421-018-0792-x

Jakubowski, K., \& Eerola, T. (2021). Music Evokes Fewer but More Positive Autobiographical Memories Than Emotionally Matched Sound and Word Cues. Journal of Applied Research in Memory and Cognition. https://doi.org/10.1016/j.jarmac.2021.09.002 
1635 Jakubowski, K., Eerola, T., Tillmann, B., Perrin, F., \& Heine, L. (2020). A Cross-Sectional Study of

1636

1637

1638

1639

1640

1641

1642

1643

1644

1645

1646

1647

1648

1649

1650

1651

1652

1653

1654

1655

Reminiscence Bumps for Music-Related Memories in Adulthood. Music \& Science, 3, 13. https://doi.org/10.1177/2059204320965058

Jakubowski, K., \& Ghosh, A. (2019). Music-evoked autobiographical memories in everyday life. Psychology of Music, 649-666. https://doi.org/10.1177/0305735619888803

Janata, P. (2005). Brain Networks That Track Musical Structure. Annals of the New York Academy of Sciences, 1060(1), 111-124. https://doi.org/10.1196/annals.1360.008

Janata, P. (2009). The Neural Architecture of Music-Evoked Autobiographical Memories. Cerebral Cortex, bhp008. https://doi.org/10.1093/cercor/bhp008

Janata, P., Tillmann, B., \& Bharucha, J. J. (2002). Listening to polyphonic music recruits domaingeneral attention and working memory circuits. Cognitive, Affective, \& Behavioral Neuroscience, 2(2), 121-140. https://doi.org/10.3758/CABN.2.2.121

Janata, P., Tomic, S. T., \& Rakowski, S. K. (2007). Characterisation of music-evoked autobiographical memories. Memory, 15(8), 845-860.

https://doi.org/10.1080/09658210701734593

Kasdan, A., \& Kiran, S. (2018). Please don't stop the music: Song completion in patients with aphasia. Journal of Communication Disorders, 75, 72-86.

https://doi.org/10.1016/j.jcomdis.2018.06.005

Kathios, N., Sachs, M. E., Zhang, E., Ou, Y., \& Loui, P. (2022). Generating New Musical Preferences from Hierarchical Mapping of Predictions to Reward (p. 2022.06.17.496615). bioRxiv. https://doi.org/10.1101/2022.06.17.496615 
1656 Kay, M. (2022). tidybayes: Tidy Data and Geoms for Bayesian Models (v3.0.2). Zenodo.

1657

1658

1659

1660

1661

1662

1663

1664

1665

1666

1667

1668

1669

1670

1671

1672

1673

1674

1675

1676

https://doi.org/10.5281/ZENODO.1308151

Koger, S. M., Chapin, K., \& Brotons, M. (1999). Is Music Therapy an Effective Intervention for Dementia? A Meta-Analytic Review of Literature. Journal of Music Therapy, 36(1), 2-15. https://doi.org/10.1093/jmt/36.1.2

Kopelman, M. D., Wilson, B. A., \& Baddeley, A. D. (1989). The autobiographical memory interview: A new assessment of autobiographical and personal semantic memory in amnesic patients. Journal of Clinical and Experimental Neuropsychology, 11(5), 724-744. https://doi.org/10.1080/01688638908400928

Krumhansl, C. L. (2017). Listening Niches across a Century of Popular Music. Frontiers in Psychology, 8. https://doi.org/10.3389/fpsyg.2017.00431

Krumhansl, C. L., \& Zupnick, J. A. (2013). Cascading Reminiscence Bumps in Popular Music. Psychological Science, 24(10), 2057-2068. https://doi.org/10.1177/0956797613486486

Kruschke, J. K. (2021). Bayesian Analysis Reporting Guidelines. Nature Human Behaviour, 5(10), Article 10. https://doi.org/10.1038/s41562-021-01177-7

Kubit, B. M., \& Janata, P. (2022). Spontaneous mental replay of music improves memory for incidentally associated event knowledge. Journal of Experimental Psychology. General, 151(1), 1-24. https://doi.org/10.1037/xge0001050

Lalla, A., Tarder-Stoll, H., Hasher, L., \& Duncan, K. (2022). Aging shifts the relative contributions of episodic and semantic memory to decision-making. Psychology and Aging. https://doi.org/10.1037/pag0000700 
1677 Larkin, M. (2001). Music tunes up memory in dementia patients. The Lancet, 357(9249), 47.

1678

1679

1680

1681

1682 1683

1684

1685

1686

1687

1688

1689

1690

1691

1692

1693

1694

1695

1696

1697 https://doi.org/10.1016/S0140-6736(05)71549-X

Levine, B., Svoboda, E., Hay, J. F., Winocur, G., \& Moscovitch, M. (2002). Aging and autobiographical memory: Dissociating episodic from semantic retrieval. Psychology and Aging, 17(4), 677-689.

Loui, P. (2020). Neuroscientific Insights for Improved Outcomes in Music-based Interventions. Music \& Science, 3, 2059204320965065. https://doi.org/10.1177/2059204320965065

Ludbrook, J. (2000). Multiple inferences using confidence intervals. Clinical and Experimental Pharmacology \& Physiology, 27(3), 212-215. https://doi.org/10.1046/j.14401681.2000.03223.x

Meeter, M., Murre, J. M. J., \& Talamini, L. M. (2004). Mode shifting between storage and recall based on novelty detection in oscillating hippocampal circuits. Hippocampus, 14(6), 722-741. https://doi.org/10.1002/hipo.10214

Merrett, D. L., Zumbansen, A., \& Peretz, I. (2019). A theoretical and clinical account of music and aphasia. Aphasiology, 33(4), 379-381. https://doi.org/10.1080/02687038.2018.1546468

Michael Rossato-Bennett (Director). (2014). Alive Inside [Documentary]. Netflix. http://www.aliveinside.us/

Miranda, D., Blais-Rochette, C., Vaugon, K., Osman, M., \& Arias-Valenzuela, M. (2015). Towards a cultural-developmental psychology of music in adolescence. Psychology of Music, 43(2), 197-218. https://doi.org/10.1177/0305735613500700 
1698 Moreton, B. J., \& Ward, G. (2010). Time scale similarity and long-term memory for autobiographical events. Psychonomic Bulletin \& Review, 17(4), 510-515.

1700 https://doi.org/10.3758/PBR.17.4.510

1701 Narme, P., Clément, S., Ehrlé, N., Schiaratura, L., Vachez, S., Courtaigne, B., Munsch, F., \& Samson, S. (2014). Efficacy of Musical Interventions in Dementia: Evidence from a

1703 Randomized Controlled Trial. Journal of Alzheimer's Disease, 38(2), 359-369.

1704 https://doi.org/10.3233/JAD-130893

1705 Nasreddine, Z. S., Phillips, N. A., Bédirian, V., Charbonneau, S., Whitehead, V., Collin, I., 1706 Cummings, J. L., \& Chertkow, H. (2005). The Montreal Cognitive Assessment, MoCA: A Brief Screening Tool For Mild Cognitive Impairment. Journal of the American Geriatrics

1708 Society, 53(4), 695-699. https://doi.org/10.1111/j.1532-5415.2005.53221.x

1709 Nelson, K. (2018). The cultural construction of memory in early childhood. Handbook of Culture 1710 and Memory, 2018, ISBN 9780190230821, Págs. 185-208, 185-208.

1711 https://dialnet.unirioja.es/servlet/articulo?codigo=7144589

1712 Newcombe, N. S., Drummey, A. B., Fox, N. A., Lie, E., \& Ottinger-Alberts, W. (2000). Remembering Early Childhood: How Much, How, and Why (or Why Not). Current Directions in Psychological Science, 9(2), 55-58. https://doi.org/10.1111/1467-

1715 8721.00060

1716 Nineuil, C., Dellacherie, D., \& Samson, S. (2020). The Impact of Emotion on Musical Long-Term 1717 Memory. Frontiers in Psychology, 11. https://doi.org/10.3389/fpsyg.2020.02110 
1718 Orben, A., \& Przybylski, A. K. (2019). The association between adolescent well-being and digital 1719 technology use. Nature Human Behaviour, 3(2), 173-182.

1720 https://doi.org/10.1038/s41562-018-0506-1

1721 Palisson, J., Roussel-Baclet, C., Maillet, D., Belin, C., Ankri, J., \& Narme, P. (2015). Music

1722 enhances verbal episodic memory in Alzheimer's disease. Journal of Clinical and 1723 Experimental Neuropsychology, 37(5), 503-517.

1724 https://doi.org/10.1080/13803395.2015.1026802

1725 Palombo, D., Te, A., Checknita, K., \& Madan, C. R. (2020). Exploring the Facets of Emotional 1726 Episodic Memory: Remembering 'What', 'Where', and 'When' [Preprint]. PsyArXiv. https://doi.org/10.31234/osf.io/ru2xz

1728 Patil, A., \& Duncan, K. (2018). Lingering Cognitive States Shape Fundamental Mnemonic 1729 1730 Abilities. Psychological Science, 29(1), 45-55. https://doi.org/10.1177/0956797617728592

1731 Peck, Katlyn. J., Girard, Todd. A., Russo, Frank. A., \& Fiocco, Alexandra. J. (2016). Music and 1732 1733 Memory in Alzheimer's Disease and The Potential Underlying Mechanisms. Journal of Alzheimer's Disease : JAD, 51(4), 949-959. https://doi.org/10.3233/JAD-150998

1734 Pendlebury, S. T., Welch, S. J. V., Cuthbertson, F. C., Mariz, J., Mehta, Z., \& Rothwell, P. M. 1735 (2013). Telephone assessment of cognition after transient ischemic attack and stroke: $1736 \quad$ Modified telephone interview of cognitive status and telephone Montreal Cognitive 1737 Assessment versus face-to-face Montreal Cognitive Assessment and neuropsychological 1738 battery. Stroke, 44(1), 227-229. https://doi.org/10.1161/STROKEAHA.112.673384 
1739 Peretz, I. (2006). The nature of music from a biological perspective. Cognition, 100(1), 1-32.

1740 https://doi.org/10.1016/j.cognition.2005.11.004

1741 Peretz, I., Gaudreau, D., \& Bonnel, A.-M. (1998). Exposure effects on music preference and recognition. Memory \& Cognition, 26(5), 884-902. https://doi.org/10.3758/BF03201171

1743 Pillemer, D. B., \& White, S. H. (1989). Childhood Events Recalled by Children and Adults. In H. W. Reese (Ed.), Advances in Child Development and Behavior (Vol. 21, pp. 297-340). JAI. https://doi.org/10.1016/S0065-2407(08)60291-8

1746 Piolino, P., Desgranges, B., \& Eustache, F. (2009). Episodic autobiographical memories over the course of time: Cognitive, neuropsychological and neuroimaging findings. Neuropsychologia, 47(11), 2314-2329. https://doi.org/10.1016/j.neuropsychologia.2009.01.020

1750 Platz, F., Kopiez, R., Hasselhorn, J., \& Wolf, A. (2015). The impact of song-specific age and 1751 affective qualities of popular songs on music-evoked autobiographical memories (MEAMs). Musicae Scientiae, 19(4), 327-349. https://doi.org/10.1177/1029864915597567

Quinci, M. A., Belden, A., Goutama, V., Gong, D., Hanser, S., Donovan, N. J., Geddes, M., \& Loui, 1755 P. (2022). Longitudinal changes in auditory and reward systems following receptive https://doi.org/10.1038/s41598-022-15687-5

1758 Ratovohery, S., Baudouin, A., Gachet, A., Palisson, J., \& Narme, P. (2018). Is music a memory 1759 booster in normal aging? The influence of emotion. Memory, 26(10), 1344-1354. https://doi.org/10.1080/09658211.2018.1475571 
1761 Ratovohery, S., Baudouin, A., Palisson, J., Maillet, D., Bailon, O., Belin, C., \& Narme, P. (2019).

1762

1763

1764

1765

1766

1767

1768

1769

1770

1771

1772

1773

1774

1775

1776

1777

1778

1779

1780

1781

Music as a mnemonic strategy to mitigate verbal episodic memory in Alzheimer's disease: Does musical valence matter? Journal of Clinical and Experimental Neuropsychology, 41(10), 1060-1073. https://doi.org/10.1080/13803395.2019.1650897

Rubin, D. C., \& Schulkind, M. D. (1997). The distribution of autobiographical memories across the lifespan. Memory \& Cognition, 25(6), 859-866. https://doi.org/10.3758/BF03211330

Salakka, I., Pitkäniemi, A., Pentikäinen, E., Mikkonen, K., Saari, P., Toiviainen, P., \& Särkämö, T. (2021). What makes music memorable? Relationships between acoustic musical features and music-evoked emotions and memories in older adults. PLOS ONE, 16(5), e0251692. https://doi.org/10.1371/journal.pone.0251692

Sambandham, M., \& Schirm, V. (1995). Music as a nursing intervention for residents with Alzheimer's Disease in long-term care: Music may be a memory trigger for patients with Alzheimer's and provide a means of communication. Geriatric Nursing, 16(2), 79-83. https://doi.org/10.1016/S0197-4572(05)80011-4

Samson, S., \& Zatorre, R. J. (1991). Recognition memory for text and melody of songs after unilateral temporal lobe excision: Evidence for dual encoding. Journal of Experimental Psychology: Learning, Memory and Cognition, 793-804.

Sánchez, A., Maseda, A., Marante-Moar, M. P., de Labra, C., Lorenzo-López, L., \& Millán-Calenti, J. C. (2016). Comparing the Effects of Multisensory Stimulation and Individualized Music Sessions on Elderly People with Severe Dementia: A Randomized Controlled Trial. Journal of Alzheimer's Disease, 52(1), 303-315. https://doi.org/10.3233/JAD-151150 
1782 Sartori, G., Snitz, B. E., Sorcinelli, L., \& Daum, I. (2004). Remote memory in advanced

1783 Alzheimer's disease. Archives of Clinical Neuropsychology, 19(6), 779-789.

1784 https://doi.org/10.1016/j.acn.2003.09.007

1785 Schiller, D., Eichenbaum, H., Buffalo, E. A., Davachi, L., Foster, D. J., Leutgeb, S., \& Ranganath, C.

1786 (2015). Memory and Space: Towards an Understanding of the Cognitive Map. The

1787 Journal of Neuroscience: The Official Journal of the Society for Neuroscience, 35(41),

1788 13904-13911. https://doi.org/10.1523/JNEUROSCI.2618-15.2015

1789 Schlagman, S., Kvavilashvili, L., \& Schulz, J. (2007). Chapter 5 - Effects of Age on Involuntary

1790 Autobiographical Memories. In Involuntary Memory (pp. 87-112). John Wiley \& Sons,

$1791 \quad$ Ltd. https://doi.org/10.1002/9780470774069.ch5

1792 Schlaug, G., Marchina, S., \& Norton, A. (2008). From Singing to Speaking: Why Singing May Lead

1793 to Recovery of Expressive Language Function in Patients with Broca's Aphasia. Music

1794 Perception: An Interdisciplinary Journal, 25(4), 315-323.

$1795 \quad$ https://doi.org/10.1525/mp.2008.25.4.315

1796 Schlaug, G., Norton, A., Marchina, S., Zipse, L., \& Wan, C. Y. (2010). From singing to speaking:

1797 Facilitating recovery from nonfluent aphasia. Future Neurology, 5(5), 657-665.

$1798 \quad$ https://doi.org/10.2217/fnl.10.44

1799 Schubert, E. (2016). Does recall of a past music event invoke a reminiscence bump in young

1800 adults? Memory, 24(7), 1007-1014. https://doi.org/10.1080/09658211.2015.1061014

1801 Schulkind, M. D., Hennis, L. K., \& Rubin, D. C. (2013). Music, emotion, and autobiographical 1802 memory: They're playing your song. Memory \& Cognition, 27(6), 948-955.

$1803 \quad$ https://doi.org/10.3758/BF03201225 
1804 Schulz, K. F., \& Grimes, D. A. (2002). Blinding in randomised trials: Hiding who got what. Lancet

1805

1806

1807

1808

1809

1810

1811

1812

1813

1814

1815

1816

1817

1818

1819

1820

1821

1822

1823

1824 (London, England), 359(9307), 696-700. https://doi.org/10.1016/S0140-6736(02)078169

Semkovska, M., Noone, M., Carton, M., \& McLoughlin, D. M. (2012). Measuring consistency of autobiographical memory recall in depression. Psychiatry Research, 197(1), 41-48. https://doi.org/10.1016/j.psychres.2011.12.010

Serafine, M. L., Davidson, J., Crowder, R. G., \& Repp, B. H. (1986). On the nature of melody-text integration in memory for songs. Journal of Memory and Language, 25(2), 123-135. https://doi.org/10.1016/0749-596X(86)90025-2

Sheldon, S., \& Donahue, J. (2017). More than a feeling: Emotional cues impact the access and experience of autobiographical memories. Memory \& Cognition, 45(5), 731-744. https://doi.org/10.3758/s13421-017-0691-6

Sheldon, S., Williams, K., Harrington, S., \& Otto, A. R. (2020). Emotional cue effects on accessing and elaborating upon autobiographical memories. Cognition, 198, 104217. https://doi.org/10.1016/j.cognition.2020.104217

Simonsohn, U., Simmons, J., \& Nelson, L. (2015). Specification Curve: Descriptive and Inferential Statistics on All Reasonable Specifications. Marketing Papers. https://doi.org/10.2139/ssrn.2694998

Simpson, S., \& Sheldon, S. (2019). Testing the impact of emotional mood and cue characteristics on detailed autobiographical memory retrieval. Emotion (Washington, D.C.), 20(6), 965979. https://doi.org/10.1037/emo0000603 
1825 Smith, S. M., \& Vela, E. (2001). Environmental context-dependent memory: A review and meta$1826 \quad$ analysis. Psychonomic Bulletin \& Review, 8(2), 203-220. https://doi.org/10.3758/BF03196157

1828 Spivack, S., Philibotte, S. J., Spilka, N. H., Passman, I. J., \& Wallisch, P. (2019). Who remembers the Beatles? The collective memory for popular music. PLOS ONE, 14(2), e0210066. https://doi.org/10.1371/journal.pone.0210066

1831

1832

1833 1834 1835 1836 1837 1838 1839 1840 1841 1842 1843

1844 Tarder-Stoll, H., Jayakumar, M., Dimsdale-Zucker, H. R., Günseli, E., \& Aly, M. (2020). Dynamic 1845 1846

St. Jacques, P., \& Levine, B. (2007). Ageing and autobiographical memory for emotional and neutral events. Memory, 15(2). https://doi.org/10.1080/09658210601119762

Stalinski, S. M., \& Schellenberg, E. G. (2013). Listeners remember music they like. Journal of Experimental Psychology: Learning, Memory, and Cognition, 39(3), 700. https://doi.org/10.1037/a0029671

Steegen, S., Tuerlinckx, F., Gelman, A., \& Vanpaemel, W. (2016). Increasing Transparency Through a Multiverse Analysis. Perspectives on Psychological Science, 11(5), 702-712. https://doi.org/10.1177/1745691616658637

Stras, L. (Ed.). (2011). She's So Fine: Reflections on Whiteness, Femininity, Adolescence and Class in 1960s Music (1st Edition). Routledge.

Talamini, F., Eller, G., Vigl, J., \& Zentner, M. (2022). Musical emotions affect memory for emotional pictures. Scientific Reports, 12(1), Article 1. https://doi.org/10.1038/s41598022-15032-w internal states shape memory retrieval. Neuropsychologia, 138, 107328. https://doi.org/10.1016/j.neuropsychologia.2019.107328 
1847 Taylor, D. B. (1997). Biomedical Foundations of Music as Therapy. MMB Music.

1848 Thaut, M., \& Hoemberg, V. (2014). Handbook of Neurologic Music Therapy. Oxford University 1849 Press.

1850 Thomas, K. S., Baier, R., Kosar, C., Ogarek, J., Trepman, A., \& Mor, V. (2017). Individualized

1851

1852

1853

1854

1855

1856

1857

1858

1859

1860

1861

1862

1863

1864

1865

1866

1867

1868
Music Program is Associated with Improved Outcomes for U.S. Nursing Home Residents with Dementia. The American Journal of Geriatric Psychiatry, 25(9), 931-938.

https://doi.org/10.1016/j.jagp.2017.04.008

Tucker, A. M., \& Stern, Y. (2011). Cognitive Reserve in Aging. Current Alzheimer Research, 8(4), 354-360. https://doi.org/10.2174/156720511795745320

Tulving, E. (1972). Episodic and semantic memory. In Organization of memory (pp. xiii, 423-xiii, 423). Academic Press.

Tulving, E. (1983). Elements of Episodic Memory. Oxford University Press.

Tulving, E., \& Thomson, D. M. (1973). Encoding specificity and retrieval processes in episodic memory. Psychological Review, 80, 352-373. https://doi.org/10.1037/h0020071

Turkkan, N., \& Pham-Gia, T. (1993). Computation of the highest posterior density interval in bayesian analysis. Journal of Statistical Computation and Simulation, 44(3-4), 243-250. https://doi.org/10.1080/00949659308811461

Usher, J. A., \& Neisser, U. (1993). Childhood Amnesia and the Beginnings of Memory for Four Early Life Events. Journal of Experimental Psychology: General, 122(2), 155. https://doi.org/10.1037/0096-3445.122.2.155

van de Schoot, R., Depaoli, S., King, R., Kramer, B., Märtens, K., Tadesse, M. G., Vannucci, M., Gelman, A., Veen, D., Willemsen, J., \& Yau, C. (2021). Bayesian statistics and modelling. 
1869

1870

1871

1872

1873

1874

1875

1876

1877

1878

1879

1880

1881

1882

1883

1884

1885

1886

1887

1888

1889

Nature Reviews Methods Primers, 1(1), Article 1. https://doi.org/10.1038/s43586-020-

00001-2

Wall, M., \& Duffy, A. (2010). The effects of music therapy for older people with dementia. British Journal of Nursing, 19(2), 108-113.

https://doi.org/10.12968/bjon.2010.19.2.46295

Wallace, W. T. (1991). Jingles in Advertisements: Can They Improve Recall? ACR North American Advances, 18, 239-24.

Wallace, W. T. (1994). Memory for Music: Effect of Melody on Recall of Text. Journal of Experimental Psychology: Learning, Memory, and Cognition, 20(6), 1471-1485.

Wan, C. Y., \& Schlaug, G. (2010). Music Making as a Tool for Promoting Brain Plasticity across the Life Span. The Neuroscientist, 16(5), 566-577. https://doi.org/10.1177/1073858410377805

Wardell, V., Esposito, C. L., Madan, C. R., \& Palombo, D. J. (2020). Semi-automated transcription and scoring of autobiographical memory narratives. Behavior Research Methods, 507517. https://doi.org/10.3758/s13428-020-01437-w

Wardell, V., Madan, C. R., Jameson, T. J., Cocquyt, C., Checknita, K., Liu, H., \& Palombo, D. (2020). Emotional Autobiographical Recollection: The Devil is in the Details [Preprint]. PsyArXiv. https://doi.org/10.31234/osf.io/pbdr5

Wickham, H., Averick, M., Bryan, J., Chang, W., McGowan, L. D., François, R., Grolemund, G., Hayes, A., Henry, L., Hester, J., Kuhn, M., Pedersen, T. L., Miller, E., Bache, S. M., Müller, K., Ooms, J., Robinson, D., Seidel, D. P., Spinu, V., ... Yutani, H. (2019). Welcome to the 
Tidyverse. Journal of Open Source Software, 4(43), 1686.

1892 Williams, J. A., Margulis, E. H., Nastase, S. A., Chen, J., Hasson, U., Norman, K. A., \& Baldassano, C. (2022). High-Order Areas and Auditory Cortex Both Represent the High-Level Event Structure of Music. Journal of Cognitive Neuroscience, 34(4), 699-714. https://doi.org/10.1162/jocn_a_01815

1896 Willoughby, K., Desrocher, M., Levine, B., \& Rovet, J. (2012). Episodic and Semantic Autobiographical Memory and Everyday Memory during Late Childhood and Early Adolescence. Frontiers in Psychology, 3. https://www.frontiersin.org/articles/10.3389/fpsyg.2012.00053 